NBER WORKING PAPER SERIES

\title{
GROWTH CYCLES
}

\author{
George Evans \\ Seppo Honkapohja \\ Paul Romer
}

NBER Working Paper 5659

\author{
NATIONAL BUREAU OF ECONOMIC RESEARCH \\ 1050 Massachusetts Avenue \\ Cambridge, MA 02138 \\ July 1996
}

We are grateful for comments received in seminars at Stanford, U.C. Berkeley, U.C. San Diego, the NBER Complementarities Group, the University of Toulouse, NYU, the University of New Orleans, UCLA, Brown, the IUPUI workshop, the University of Chicago, the Federal Reserve Bank of St. Louis, the IIES in Stockholm, and The Nordic Macroeconomics Workshop in Reykjavik, as well as detailed comments from David Romer, Peter Howitt and Paul Beaudry. We would also like to acknowledge the working group on Economic Growth of the Canadian Institute for Advanced Research, the Yrjo Jahnsson Foundation and Academy of Finland grants to the Research Unit on Economic Structures and Growth, and the SPES program of the EU. This paper is part of NBER's research program in Economic Fluctuations and Growth. Any opinions expressed are those of the authors and not those of the National Bureau of Economic Research.

(C) 1996 by George Evans, Seppo Honkapohja and Paul Romer. All rights reserved. Short sections of text, not to exceed two paragraphs, may be quoted without explicit permission provided that full credit, including $(\mathcal{O}$ notice, is given to the source. 


\title{
GROWTH CYCLES
}

\begin{abstract}
We construct a rational expectations model in which aggregate growth alternates between a low growth and a high growth state. When all agents expect growth to be slow, the returns on investment are low, and little investment takes place. This slows growth and confirms the prediction that the returns on investment will be low. But if agents expect fast growth, investment is high, returns are high, and growth is rapid. This expectational indeterminacy is induced by complementarity between different types of capital goods. In a growth cycle there are stochastic shifts between high and low growth states and agents take full account of these transitions. The rules that agents need to form rational expectations in this equilibrium are simple. The equilibrium with growth cycles is stable under the dynamics implied by a correspondingly simple learning rule.
\end{abstract}

George Evans

Department of Economics

4th Floor, PLC

University of Oregon

Eugene, OR 97403-1285

Paul Romer

Graduate School of Business

Stanford University

Stanford, CA 94305

and NBER
Seppo Honkapohja

Department of Economics

University of Helsinki

PO Box 54

00014 Helsinki

FINLAND 


\section{Introduction}

One of the oldest conjectures in economics holds that self-fulfilling shifts in optimism or confidence can destabilize aggregate economic activity. Aggregate investment, which is notoriously volatile, has long been suspected of being susceptible to these fluctuations. ${ }^{1}$ In this paper, we construct an explicit model that exhibits this kind of expectational indeterminacy in investment. In a rational expectations equilibrium, changes in expectations cause the economy to cycle back and forth between periods with high levels of investment and rapid GDP growth and periods with low levels of investment and slow GDP growth.

In the last twenty years, economists have developed a number of models with multiple perfect foresight equilibria and expectational indeterminacy. In a perfect foresight solution, expectations can determine which equilibrium is realized at time 0 , but agents form expectations on the assumption that there is no uncertainty about which equilibrium will be selected in future periods. In solutions with expectational indeterminacy agents also take account of the fact that shifts in expectations will continue to influence the behavior of the economy at all future dates. Despite the longstanding interest in the role of expectations and their apparent relevance for macroeconomic fluctuations, these models have not found a central place in macroeconomic theory.

Part of the difficulty may derive from the different goals of pure and applied theorists. Pure theorists have explored a variety of simple, artificial models that have helped to clarify how multiple equilibria and expectational indeterminacy can arise in a dynamic economy. However, some of these models have implications that strike macroeconomists as wildly implausible. For example, in monetary models, a constant money supply in a stationary economy can lead to infinitely many equilibria with explosive prices (Brock, 1975). Other results have turned out to be fragile. For example, introducing a durable asset like land into an overlapping generations model can kill any

\footnotetext{
${ }^{1}$ For evidence on the volatility of investment relative to other components of GDP and its high positive correlation with GDP, see Table 1.1 in Blanchard and Fischer (1989) or Table 1.1 in Cooley and Prescott (1995).
} 
equilibria with endogenous fluctuations. ${ }^{2}$ Macroeconomists understandably question the empirical relevance of all such models.

Our goal in this paper is to make a case for a mechanism that can generate expectational indeterminacy in real economies. This mechanism is based on micro-foundations that are familiar and plausible. It fits the traditional conjecture about investment behavior. It does not rely on controversial assumptions that make the model suspect on a priori theoretical grounds or that distract from our basic message about investment. This means that in contrast to some of the older models with expectational indeterminacy, we eschew the use of overlapping generations and assume that agents are infinitely lived. We also specify the model entirely in real terms, so there is no fiat money. We assume that markets are complete, so agents can trade securities with payoffs that are contingent on the state of the economy. We do not assume that there are search related externalities in the labor market. In a departure from many of the recent models of multiple equilibria, we do not allow any production relationship to exhibit short-run increasing returns to scale, or equivalently, to exhibit falling short-run marginal costs of production. ${ }^{3}$

We also go beyond the mere demonstration that a rational expectations equilibrium with growth cycles exists. We show that this equilibrium is locally stable under a natural learning rule. As a result, arguments about stability under learning that were used to dismiss some of the implausible monetary equilibria cannot be used to rule out the behavior we identify. Moreover, our equilibrium concept makes only modest information processing demands on our agents. They do not need to formulate expectations about complicated dynamic paths for any variables in the economy. In the high and low growth states, different GDP growth rates and market interest rates will be observed. To make correct forecasts, agents need to know only these numbers. Under the learning process, they start with estimates for them and update the estimates as they observe the realized values in the high or low growth states.

The switches between fast and slow growth states are signaled by a random policy variable. As we explain later, we think of this variable as an indicator of monetary policy, which can be restrictive or expansive. ${ }^{4}$

\footnotetext{
${ }^{2}$ See the discussion of this point in Woodford (1991).

${ }^{3}$ Section 4 contains a detailed discussion of how our model fits into the literature.

${ }^{4}$ In an empirical study Kaminsky (1993) has employed a two state classification of
} 
Because we do not introduce fiat money into our economy, monetary policy merely acts as a signal. For our purposes, it is sufficient to think of the policy variable as a traffic signal installed on the top of the Federal Reserve Bank of New York that switches between red and green. Agents learn the transition probabilities between red and green directly by watching the signal or equivalently by observing the behavior of the economy over time.

We do not treat monetary policy this way because we think that monetary non-neutralities are irrelevant or trivial. On the contrary, we intend our model as a justification for the claim that monetary disturbances with small direct effects can nevertheless have large macroeconomic consequences. Because it is simpler, we go to the limit and assume that the direct effects are vanishingly small. Bringing small direct effects back into the model would make the case for the importance of monetary policy even stronger.

The crucial assumption in the model specifies how different types of capital goods interact in production. We assume that they are complements. Their interactions are analogous to those between dump trucks and front-end loaders or between personal computers, laser printers, and digital communication networks. Having more of one type of good raises the marginal productivity of the others. The ultimate result from the model is exactly what an intuition based on the notion of strategic complementarity would suggest. ${ }^{5}$ If the quantities of capital goods that are complements with your good are going up, this raises the marginal productivity of your good. Hence, at constant prices, the quantity demanded goes up. Therefore, you produce more, just like everyone else. If you are already in business, you expand output faster than you would otherwise have done. If you are not yet in business, now is the time to enter. In our equilibrium, this self-reinforcing process is strong enough to be self-sustaining.

This intuition captures the essence of the argument, but the details are not simple. By itself, complementarity between different types of investment goods is not enough to generate growth cycles. An argument first outlined by Cass and Shell (1983) shows that the kind of expectational indeterminacy exhibited by our model cannot arise if the model satisfies all of the assumptions required to prove that equilibria are Pareto optimal. We make only one departure from the standard assumptions. We introduce

\footnotetext{
FOMC announcements into "expansionary" and "restrictive" monetary policy regimes.

${ }^{5}$ See Cooper and John (1988) for a discussion of the concept of strategic complementarity.
} 
a nonconvexity. Specifically, we assume that a firm must incur a fixed research and development cost before it can produce a new type of investment good. Producers of investment goods have patent rights over the designs that result. They charge the simple monopoly price for their goods. Physical units of the investment goods are produced under conditions of constant returns to scale. This is characterized by falling average cost but constant marginal cost. Each monopolist also faces a constant elasticity demand curve, so prices are a constant markup over cost. The resulting equilibrium is characterized by a familiar form of monopolistic competition with a large number of small firms. Again, in contrast to other models, we do not allow for any strategic interactions between firms. The elasticity of demand faced by any monopolist does not change over time. The demand curve faced by each monopolist has no kinks. All these other elements and more could be added to the model, but they are not central to the story that we tell.

Our immediate goal is to show that by themselves, our two basic assumptions - complementarity of investment goods and endogenous innovation motivated by monopoly power - are sufficient to generate robust, endogenous fluctuations in aggregate investment. To make our point as simply and as convincingly as possible, we abstract from many issues that would be important in a complete model of business cycle fluctuations and macroeconomic policy. For example, a more realistic specification would allow for many different kinds of capital goods, some of which are substitutes for each other (mini-computers and desktop computers) and some of which are complements with each other (computers and laser printers). Alwyn Young (1993) uses this kind of model in his demonstration that multiple perfect foresight endogenous growth rates are possible. ${ }^{6}$ We use a specification that allows only for complements because it simplifies the formal analysis when we undertake the difficult task of constructing a rational expectations model with endogenous switching between growth rates. (We return to a discussion of complementarity and substitution in the concluding section since this issue is central to any attempt to gauge the aggregate importance of complementarities.) We also assume that the supply of labor is fixed and that the labor market always clears. Finally, as we have already noted, we do not allow for any real effects associated with monetary policy.

\footnotetext{
${ }^{6}$ Strictly speaking, this is true in Young's model if one reinterprets the utility function for each type of good in his model as being a part of the technology, so that a what he calls the utility from each good is a kind of produced output.
} 
These last two assumptions make our model simpler and our results even stronger. If we allowed for more complicated labor market dynamics or for nominal non-neutralities, the set of possible fluctuations would be even richer. Our simple model is more useful for our theoretical purposes, but it is clearly too restrictive for policy analysis. A trivial implication of the model as it stands is that welfare is always higher when monetary policy is expansive. We recognize that a complete treatment of monetary policy would take account of its effects on inflation. We also understand that unemployment is a real feature of the labor market that a more complete model would have to address.

Because of the simplifying assumptions that we make, we do not believe that our model is one that can be taken directly to the data. In this sense, our ambition is more modest than that of authors who have tried to justify the empirical plausibility of key parameters or to calibrate models with various forms of indeterminacy. Our sense is that the main task now is to make a convincing case for the plausibility of an underlying mechanism that is capable of generating expectational indeterminacy. Calibration and empirical testing will come later. ${ }^{7}$

At present, the main competitor with the mechanism based on complementarity that we emphasize is short-run increasing returns to scale. Although there are macroeconomic estimates which suggest that this kind of increasing return might be present, these estimates are controversial. ${ }^{8}$ As a result, microeconomic evidence is likely to play a decisive role in establishing or refuting the plausibility of any proposed mechanism. We suspect that the microeconomic evidence concerning complementarities will ultimately prove to be more compelling than evidence about short-run, increasing returns to scale and falling short-run marginal cost. This is why we emphasize complementarities. In the concluding section, we describe how the model needs to be extended before questions about plausible parameter values can realistically be addressed.

Despite our best efforts, the complete model is still fairly complicated. We develop it in stages. We start in Section 2 by describing the underlying perfect-foresight, balanced-growth model. Under the assumption that there is no uncertainty, we show that from any initial condition, this model poss-

\footnotetext{
${ }^{7}$ See Benhabib and Rustichini (1994) for the contrary argument, that calibration is the next order of business for macroeconomists interested in models with multiple equilibria.

${ }^{8}$ See for example, the discussion in Benhabib and Farmer (1994).
} 
eses three possible balanced growth paths. Two of the three perfect foresight growth rates are stable under learning. We look in a neighborhood of these for our high and low growth states in the extension with random switches.

Then, in Section 3, we describe the extension that brings uncertainty into the model and converts it from a model with multiple perfect foresight equilibria into a fully specified model with expectational indeterminacy. We introduce a policy variable that is a two-state Markov process. One state signals expansion. The other signals contraction. In equilibrium, all agents understand that all other agents rely on this signal to predict whether the economy is currently in a high or low growth state. We calculate the equilibrium, letting agents take account of the random switches between future growth rates that will now be present. The previous analysis of distinct perfect foresight equilibria thereby becomes a special case of the analysis of a single stochastic rational expectations equilibrium that alternates between high and low growth states. Finally, we verify that this rational expectations equilibrium is stable under learning. Specifically, we prove an existence result demonstrating that a locally stable equilibrium must exist. We also compute an explicit example and use the learning algorithm as a numerical procedure to calculate the equilibrium growth and interest rates.

\section{The Perfect Foresight Growth Model}

\subsection{Modeling Strategy}

Because the equilibria of interest to us are not Pareto optimal, we cannot calculate them by solving an optimization problem. Because we do not want to restrict attention to the behavior of the economy in the neighborhood of a steady state, we cannot simplify the system of equations that determine a dynamic equilibrium by linearizing around a steady state. We will therefore be forced to find distinct, explicit solutions to an infinite system of equations in an infinite number of unknowns. To keep things manageable, we will make use of a few key simplifying assumptions that let us reduce this infinite dimensional problem to an equivalent finite dimensional problem.

The two most important simplifying assumptions are that there is a single state variable and that the preferences and technology are homogeneous. As we will show, this means that the economy looks the same at every date. 
The only difference is that all opportunities are scaled up by the stock of the single state variable. In effect, this reduces the problem of calculating an infinite path for dated consumption goods and dated stocks of capital to the simpler, finite dimensional problem of calculating the constant proportional amount by which consumption and the state variable grow in each period. If we had more than one state variable, we would have to be concerned with transition dynamics associated with changes in the ratios of two or more state variables.

The homogeneity that we need is an inherent feature of any model that generates balanced growth - that is, in which all quantities grow at constant exponential rates. We will build our model using pieces that are familiar from existing models of balanced growth.

Our preference structure is standard. We assume that there is a representative consumer who maximizes the discounted expression for utility,

$$
\sum_{i=0}^{\infty} \beta^{t+i} U\left(C_{t+i}\right)
$$

When we introduce uncertainty later in the paper, the consumer will maximize expected utility. We also use the standard isoelastic expression for the utility derived from consumption in each period: $U(C)=\frac{C^{1-\sigma}}{1-\sigma}$. This specification gives us the homogeneity we need on the preference side of the model. A consumer who is faced with a constant interest rate $r$, will choose to have consumption grow at the constant rate $g_{c}$ given by

$$
g_{c}=\frac{C_{t+1}}{C_{t}}=\left[\beta\left(1+r_{t}\right)\right]^{1 / \sigma} .
$$

We will characterize our infinite dimensional equilibria in terms of two equations in two endogenous variables: the interest rate and the rate of growth. This expression gives us one of the two relationships. The second comes from an arbitrage condition from the technology side of the model. Because our technology is complicated, we proceed in steps, illustrating the relationships between $r$ and $g$ that emerge in simpler models and working up to the relationship for our full model. 


\subsection{Linear Production}

The simplest production structure is one in which output is linear in the stock of capital and in which there is a one-for-one trade-off between new capital and consumption:

$$
\begin{aligned}
Y_{t} & =B K_{t} \\
K_{t+1}-K_{t} & =Y_{t}-C_{t} .
\end{aligned}
$$

This is an example of what is now called an " $A K$ " or linear growth model. (We use the symbol " $B$ " instead of " $A$ " to avoid confusion with a later use of $A$.) The correct interpretation of this accumulation equation is that consumption goods and capital goods are produced in different sectors that use the same production technology. In this case, the production possibility frontier between additions to the capital stock and units of consumption goods is linear. The model can therefore be treated as if it has a single productive sector. By a suitable choice of units, the trade-off between capital and consumption goods can be taken to be one-for-one.

The behavior of this trivial model can be characterized by a graph that plots the equilibrium interest rate as a function of the equilibrium growth rate as in Figure 1. The upward sloping curve in this plot comes from equation (1) and is labeled the preference curve. The horizontal line, which is labeled "one sector technology" is determined by arbitrage on the production side of the model. Arbitrage implies the equality $r=B$. The intersection determines the equilibrium interest rate and growth rate. Because of the homogeneity of the model, the implied values for $r$ and $g$ determine everything about the equilibrium starting from any initial stock of capital $K_{0}$.

A second "technology" curve, which is downward sloping, characterizes the no-arbitrage condition when the production functions for producing consumption and capital goods are different. Suppose that the production possibility frontier between additions to the stock of capital and consumption is nonlinear. The traditional way to specify this would be to assume a functional form for production in each sector and derive the expression for the production possibility frontier. Instead, we take a short-cut by assuming a simple functional form for the production possibility frontier itself. Let $Y_{t}$ denote the maximum feasible amount of consumption goods that 


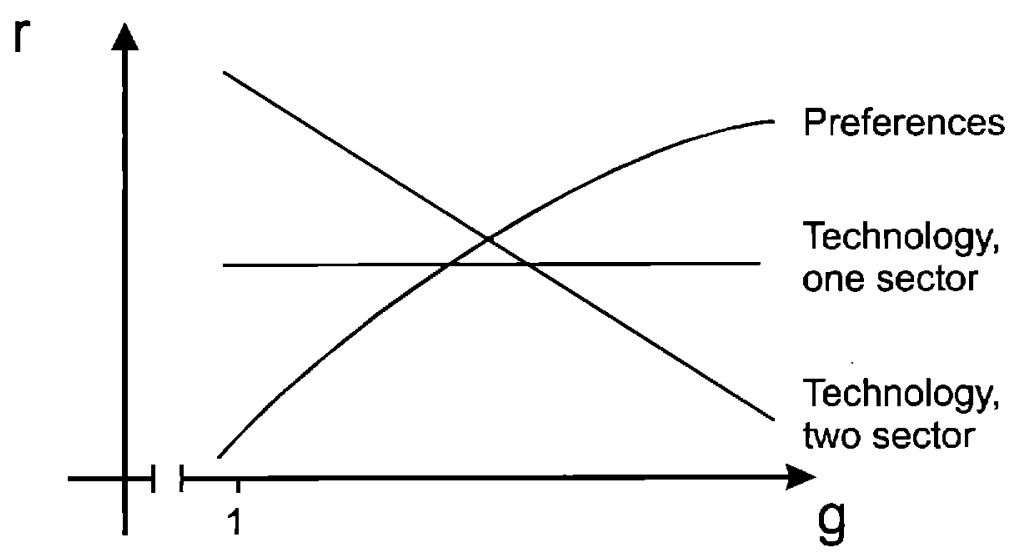

Figure 1: Perfect foresight equilibria under two different technologies

can be produced. Suppose that output of consumption goods is related to increases in the capital stock as follows:

$$
C_{t}=Y_{t}-K_{t} \chi\left(\frac{K_{t+1}-K_{t}}{K_{t}}\right)
$$

In the expression, $\chi($.$) can be any increasing, convex cost function with$ $\chi(0)=0$. Note that this kind of specification imposes the homogeneity of degree one in the state variable $K$ that we need on the production side of the model. Note also that this reduces to equation (3) in the case where $\chi$ is the identity function. With this specification, the price of capital goods in units of consumption goods will be the derivative of consumption with respect to the stock of capital tomorrow, which we can write as $\chi^{\prime}\left(g_{K}\right)$, where $g_{K}=\frac{K_{t+1}-K_{t}}{K_{t}}$. One unit of consumption can now be invested to yield $r$ units of additional consumption goods in each period. Alternatively, it can be used to purchase $\chi^{\prime}\left(g_{K}\right)^{-1}$ units of capital, which will yield a flow of $B$ units of consumption goods in each period. Thus, a no-arbitrage condition on the technology side of the model imposes the equality $r=\frac{B}{\chi^{l}\left(g_{K}\right)}$. Because $\chi($. is convex, this expression yields the downward sloping curve labeled "two 
sector technology" in Figure 1.

Two features of this kind of model make this simple diagrammatic characterization of equilibria possible for both of these models. First, the accumulation equation for capital, (3) or (4), implies that if capital, output, and consumption grow at constant multiplicative rates, this rate must be the same for all three variables. The equilibrium can therefore be characterized using a common growth rate $g=g_{C}=g_{K}$. Second, because of the homogeneity of the specifications for preferences and the technology, the curves in the figure do not depend on the level of the state variable $K$. These two features will carry over to elaborations of this basic structure that allow for fixed costs of invention and complementarity between types of capital goods.

\subsection{Many Capital Goods}

To bring invention into the analysis, we start with the model of growth taken from Romer (1987). This model allows for the introduction of new types of capital goods, but its equilibrium behavior closely resembles the behavior of the one-sector model described above. Output of consumption goods is a function of labor (assumed in fixed supply) and the quantities of a large number of specialized capital goods:

$$
F(L, x(.))=\int_{0}^{A} x(i)^{\alpha} d i .
$$

In this expression, the running index $i$ indexes different types of capital goods. The expression $x(i)$ denotes the number of units of capital of type $i$ that are in use. The upper limit $A$ indicates the range of capital goods that have already been designed and can therefore be produced. Although it would be more natural to let the index $i$ and the upper bound $A$ be integer valued and to replace the integral by a sum, we use the continuous version specified here to avoid the distractions associated with integer constraints.

In addition to the production of final output, there are two other productive activities - inventing new types of capital goods and producing physical machines of each of the many existing types of capital goods. By analogy with the one sector model described above, we can assume that the same production technology described by the functional $F($.$) can be used in$ all productive activities: making consumption goods, designs for new types 
of machines, and physical machines themselves. With the same production technology, the trade-off between the different types of output is linear. We can therefore denote total output (which is the same as the maximum feasible output of consumption goods) as $Y_{t}=F(L, x()$.$) . Assume that it takes$ one unit of forgone consumption to make each additional unit of any type of machine and that it takes $a$ units of forgone consumption to produce a design for an entirely new type of machine. Then total output is split according to

$$
Y_{t}=C_{t}+a\left(A_{t+1}-A_{t}\right)+K_{t+1}-K_{t},
$$

where $K_{t}$ is defined as the total stock of machines measured in units of the cost of production for these machines:

$$
K_{t}=\int_{0}^{A_{t}} x_{t}(i) d i .
$$

The market structure in this model is monopolistically competitive. Any firm that designs a new machine gets a patent on the design. It produces machines and charges the simple monopoly price for these machines. In equilibrium, the interest rate $r$ adjusts so that the present discounted value of the resulting monopoly profits is just equal to the cost $a$ of inventing a new type of machine. The zero profit condition in this equilibrium implies that at every date, the ratio of $A_{t}$ to $K_{t}$ is constant so we can work with a single aggregate state variable $Z_{t}=a A_{t}+K_{t}$ that summarizes the effects of all previous investment decisions. The accumulation equation can then be written as

$$
Y_{t}=C_{t}+Z_{t+1}-Z_{t}
$$

It turns out that the reduced form expression for output $Y$ as a function of accumulation to date $Z$ is linear in $Z$. As a result, the intertemporal zero profit condition is satisfied at a unique value of the interest rate $r$. This value of $r$ is independent of the state variable $Z_{t}$. (See Romer, 1987, for details concerning the claims made about this model.) As a result, the analysis of growth is exactly as depicted in the single sector version of the technology in Figure 1. The production technology determines a unique interest rate. The preference specification then yields the rate of growth for the economy. 


\subsection{Capital Goods that are Complements}

As the introduction makes clear, our main interest lies in capital goods that are complements with each other. To see how we can bring this into the model, note that equation (5) uses a constant-elasticity-of-substitution aggregator to summarize the effect on output of all the different types of capital goods. If we reduce the model to the special case with only two discrete capital goods, the production function takes the form

$$
F\left(L, x_{1}, x_{2}\right)=L^{1-\alpha}\left(x_{1}^{\alpha}+x_{2}^{\alpha}\right) .
$$

As it stands, this makes production additively separable in goods 1 and 2. To make them complements or substitutes, one need only introduce an additional exponent on the capital aggregate:

$$
F\left(L, x_{1}, x_{2}\right)=L^{1-\alpha}\left(x_{1}^{\gamma}+x_{2}^{\gamma}\right)^{\phi} .
$$

If we impose the restriction $\gamma \phi=\alpha$, then we preserve homogeneity of degree 1 . For values of $\phi$ greater than 1 , the two capital goods $x_{i}$ will be complements; an increase in the quantity of one raises the marginal product of the other. Generalizing this idea, we can write the many-good, continuousindex version of this expression as follows:

$$
Y_{t}=L^{1-\alpha}\left(\int_{0}^{A_{t}} x_{t}(i)^{\gamma} d i\right)^{\phi}
$$

In the additively separable model outlined above, it took a constant amount of forgone consumption to produce each design for a new type of capital good. In an extension that makes the capital goods complements, this specification for the technology for producing designs would lead to explosive growth. Later designs would be more valuable because there are more complements around that raise the value of a new capital good. The incentives for discovering new goods would then grow rapidly over time. One simple way to offset this increased incentive is to assume that there is also a higher cost for designing goods with a higher index. Specifically, we will assume that it takes $i^{\xi}$ units of forgone output to produce a design for good $i$. In equilibrium, the increased incentives for discovering new goods that 
come from complementarity will just offset the increased costs of discovery if the following parameter restriction holds:

$$
\xi=\frac{\phi-1}{1-\alpha} .
$$

If this restriction does not hold, the model will exhibit rates of growth that are locally increasing or decreasing over time. The model would be economically sensible (provided some force keeps growth rates from becoming too large), but it would no longer be possible to solve for a single, constant growth rate as we did in Figure 1 for the linear production model. The values for $r$ and $g$ would be changing over time.

Our strategy is therefore to impose this restriction (6) and look for equilibria in the subspace consisting of paths exhibiting constant exponential growth. Because our functional form is a special case of all possible functional forms and because our solution space is a subspace of all possible dynamic paths, any forms of behavior that are possible in our restricted model will a fortiori be possible in a less restrictive analysis.

In the extended model with complements, we can still write the accumulation equation for the single state variable as

$$
Y_{t}=C_{t}+Z_{t+1}-Z_{t}
$$

The only difference arises in the slightly more complicated relationship between the stock of total capital $Z$ and the other state variables. At date $t$, the expression for total capital $Z$ is

$$
Z_{t}=\int_{0}^{A_{t}} x_{t}(i) d i+\int_{0}^{A_{t}} i^{\xi} d i=K_{t}+\int_{0}^{A_{t}} i^{\xi} d i .
$$

The first term, $K_{t}$, represents cumulative total investment in machines. (So far, we have been ignoring the possibility that machines depreciate. We will introduce this complication later.) The second term describes cumulative total investment in the production or discovery of new designs.

The analysis of the perfect foresight, monopolistically competitive equilibrium for this model proceeds exactly as it did in the model where the capital goods have additively separable effects on production. (Details are given in the appendix.) The fundamental arbitrage result is derived from the intertemporal zero profit condition on investments in new designs. The 


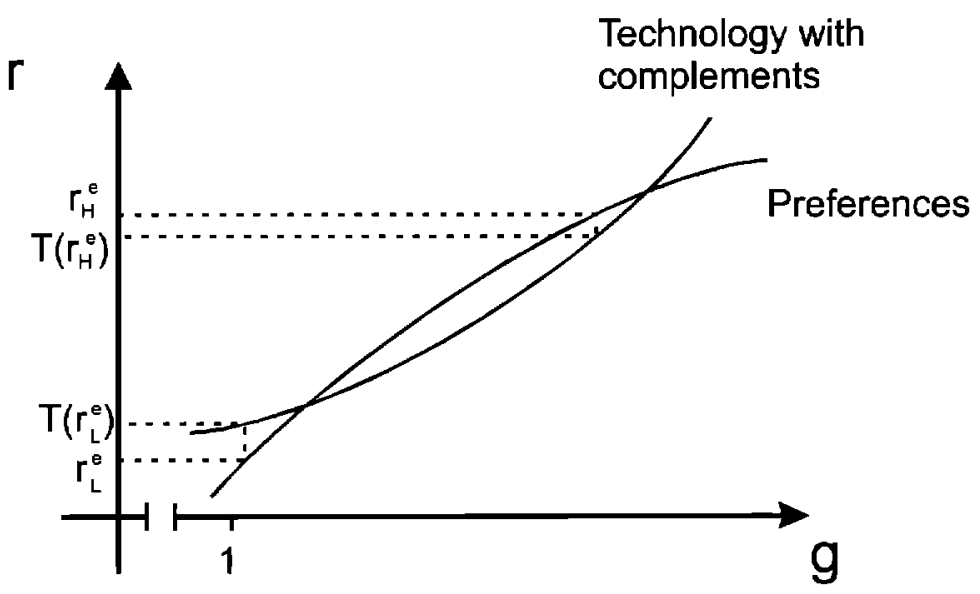

Figure 2: Perfect foresight equilibria with complementary inputs

key result that emerges from this analysis is that the no-arbitrage or zero profit relationship implied by the technology yields an upward sloping locus of $(r, g)$ pairs as illustrated in Figure 2. In this case, the growth rate $g$ refers to the common growth rate for $Y_{t}, C_{t}$, and $Z_{t}$. Because designs are getting more costly, $g_{A}$ is smaller than $g$. In fact, one can show that $g=g_{A}^{\xi+1}$. Because the preference relationship is also upward sloping, these curves may intersect more than once. For appropriate parameter values, they intersect twice, as illustrated in Figure 2. This means that the model has two distinct perfect foresight equilibria. For any given initial value of $Z_{t}$, there is one perfect foresight equilibrium in which the values for $Y_{t}, C_{t}$, and $Z_{t}$ all grow at the high rate determined by the upper intersection. There is also a second perfect foresight equilibrium in which they grow at the low rate determined by the lower intersection of the two curves.

The intuition behind the upward slope of the technology locus is fundamental to all of the results that follow. Because of the complementarity between goods, a firm that invents a new type of good today will face a demand for its good that increases with the quantities and varieties of other goods that are introduced tomorrow. Suppose that we start from an inter- 
est rate and a growth rate that yields zero intertemporal profits. Consider an increase in the rate of growth of the economy. If $K_{t}$ and $A_{t}$ grow more rapidly, the present discounted value of its stream of future profits generated by a new invention would be higher if the interest rate remained the same. Competition for resources by potential new entrants will therefore drive up the interest until the present discounted value of the future profits is driven back down to the cost of inventing a new good.

\subsection{Stability under Learning}

It is tempting to use the relatively simple model characterized in Figure 2 as the basis for a model of macroeconomic fluctuations. At any date, there is nothing that forces the economy to stay with one equilibrium or the other. One could imagine, therefore, that changes in expectations could cause the economy to switch between the high and low growth states.

This intuition is partly right, but there are two difficulties that must be faced before this argument can be made precise. First, this model is a model of multiple perfect foresight equilibria. The rate of growth at each of the two equilibria is calculated on the assumption that the economy will stay forever at that equilibrium. Once we allow for the passibility that the aggregate economy can switch between equilibria, then we must also let agents take account of this possibility when they form their expectations. We will deal explicitly with this issue in the next section, where we formally introduce a solution concept that allows for expectational indeterminacy.

The second issue suggested by the analysis in Figure 2 concerns stability. Whenever we see two equilibria in an economic model, we have come to expect that one of them will be stable and that the other will be unstable. The goal in this section is to identify the precise sense in which one can speak of an equilibrium point as being stable or unstable. Then we will modify the model so that it has three perfect foresight equilibria, two on the ends that are stable and one in the middle that is unstable.

We emphasize that it does not make sense to think of these equilibria as being stable or unstable in the usual sense. In the usual model, the quantities evolve along explicit trajectories. Which trajectory the economy follows is determined by the initial conditions. From a given initial position, the equilibrium dynamics take the economy away from some steady state points and toward others. In this setting, stability is used to distinguish 
between resting points that will be reached from a large class of initial values for the state variables and resting points that can be reached only from a measure zero set of initial values for the state variables.

This kind of analysis does not apply to our model. It has only one state variable and the dynamic equations that determine the growth rate do not depend on the level of this state variable. As a result, the initial conditions do not pin down a starting point in the $(r, g)$ space illustrated in Figure 2. For any initial value of the state variable $Z$, the economy can select either of the perfect foresight paths characterized by the intersections in the figure.

We can, however, inquire into the stability properties of the equilibria by going outside of the perfect foresight model and asking what the dynamics would be if agents had to learn about the equilibrium values of variables by observing the behavior of the economy itself. If plausible learning dynamics lead the agents away from some perfect foresight equilibria and toward other equilibria, we can use this difference to distinguish between more and less plausible perfect foresight equilibria. That is, we can use stability under the learning dynamics as a selection criterion when there are multiple equilibria.

In modeling learning, we restrict attention to a simple scheme in which households base their actions on an expected interest rate. Given their beliefs about interest rates, consumers decide how much to save. Firms observe the current savings behavior of the consumers and project this behavior into the indefinite future. Given their beliefs about current and future savings behavior, firms will compete for resources in financial markets. This determines a realized interest rate that is consistent with no-arbitrage on the production side of the market. After consumers observe the realized rates, they adjust their expectations about future interest rates. For example, if the interest rate that consumers expected was lower that the interest rate that is realized, they will revise their forecasts of interest rates upward.

Out of equilibrium, both firms and consumers make mistakes. Consumers use the wrong interest rate for their projections of current and future interest rates. Firms project the current savings behavior of consumers into the future, but consumers will modify their savings behavior as they update their estimate of the interest rate. If one of the perfect foresight equilibria is stable, this process will converge to the equilibrium if it starts from nearby values for $r$ and $g$. As it does, these mistakes become smaller. In the limit, at the equilibrium values for the interest rate and the growth rate, these rules lead to correct forecasts by both firms and consumers. Interest rates 
and growth rates are constant and no revisions are necessary.

To conduct the learning analysis it is necessary to extend the model to a temporary equilibrium framework that captures these assumptions. Fortunately, this analysis can be carried out using the same curves that characterize the equilibrium in $(r, g)$ space. Given an expected interest rate $r^{e}$, households choose their saving to generate the rate of growth of wealth and consumption implied by equation (1), the equation that determines the preference curve in Figure 2. Firms take this growth rate of consumption and the implied, and equal, growth rate of total capital $Z$ as given and project it into the future. At this expected growth rate for the economy, there is a unique realized interest rate that is consistent with no-arbitrage on the technology side of the market. This is the value of $r$ that is determined by inserting the given growth rate into the technology curve in the figure. If we take the composition of these two operations, we have a mapping that takes expected interest rates into realized interest rates. Let us denote this mapping as follows:

$$
r=T\left(r^{e}\right)
$$

By construction, the interest rates corresponding to perfect foresight balanced growth paths are fixed points of $T$.

To generate an explicit dynamics for the interest rate, we use an adaptive learning scheme,

$$
r_{t+1}^{e}=r_{t}^{e}+\delta_{t}\left(r_{t}-r_{t}^{e}\right)
$$

where $\delta_{t}=\frac{\delta}{t}$. The sequence $\left\{\delta_{t}\right\}$ is known as the gain sequence. It determines the extent of the adjustment of expectations to forecast errors. A decreasing sequence $\left\{\delta_{t}\right\}$ implies that consumers become less responsive to forecast errors as more data accumulates. For example, with $\delta=1$ and appropriate initial values, equation (9) implies that $r_{t+1}^{e}$ is equal to the average of past values of $r_{t}$. This kind of learning rule is particularly appropriate in an extension of this model which allows for small stochastic shocks, but we do not introduce these shocks explicitly into the analysis here. Together, equation (9) and the mapping $r_{t}=T\left(r_{t}^{e}\right)$ define a dynamic system which can be analyzed in the vicinity of a fixed point. (For a general discussion of these kinds of learning algorithms, see the review paper by Evans and Honkapohja, 1995a. For a discussion of learning around steady states, see Evans and Honkapohja, 1995b.) If we linearize this system around a steady 
state, we can show that the fixed point is locally stable if $T^{\prime}(r)<1$. (If the parameter $\delta_{t}$ were equal to one so that the sequence of values for $r^{e}$ was determined simply by iterates of $T$, we would have to impose the additional condition $T^{\prime}(r)>-1$. However, $\delta_{t}$ goes to zero, so we do not have to worry about instability caused by overshooting in the adjustment process.)

As experience suggests, the two equilibria in Figure 2 have different stability properties. The function $T$ is the composition of the two functions graphed in the figure. At points where they intersect, the size of $T^{\prime}$ relative to 1 is determined by the relative slopes of the two curves. A simple geometrical argument shows that it is the lower equilibrium that is stable under learning. In Figure 2, $r_{L}^{e}$ denotes an expected interest rate that is below the interest rate in the low-growth perfect foresight equilibrium and $r_{H}^{e}$ denotes an expected interest rate that is also below the interest rate in the highgrowth equilibrium. As the figure shows, when the mapping $T$ is applied to $r_{L}^{e}$, it leads to a value $T\left(r_{L}^{e}\right)$ that is above $r_{L}^{e}$, so adjustment moves the expected interest rate in the right direction. In contrast, when applied $T$ is applied to $r_{H}^{e}$, it leads to a value that is below $r_{H}^{e}$, so the learning dynamics drives the economy away from the high growth equilibrium. ${ }^{9}$

If one accepts, as we do, the notion that any perfect foresight equilibrium that is unstable under simple learning rules is unlikely to be realized in practice, one is forced to conclude that the kind of multiplicity exhibited in Figures 2 is unlikely to have any practical relevance. To have a candidate for a model with multiple stable perfect foresight equilibria, we will need a model that generates more intersections of the two curves in this figure.

\subsection{Multiple Stable Perfect Foresight Equilibria}

Careful readers will no doubt have guessed where the argument is now headed. We showed in the analysis of Figure 1 that a two-sector structure that generates a standard, nonlinear trade-off between the production of

\footnotetext{
${ }^{9}$ Note that there are alternative ways of formulating the temporary equilibrium and corresponding learning rules. For example, firms could instead have expected growth rate $g_{Z}^{\mathbf{e}}$ with the actual growth rate and interest rate in a temporary equilibrium determined by inferring $r$ from the arbitrage condition for firms from the technology side of the model, taking $g_{Z}^{e}$ as given. Next, we could let consumers select the rate of growth of consumption and wealth from off of the preference curve. A learning scheme $g_{Z, t}^{e}$ for firms could then be based on the forecast errors $g Z_{, t}-g_{Z, t}^{e}$. It can be easily verified that a steady state is stable under (9) if and only if it is stable under this alternative scheme.
} 
investment goods and consumption goods tends to make the technology curve slope down in $(r, g)$ space. We have just shown that complementarity between different types of capital goods tends to make the technology curve slope up. If we combine these two elements in the same model, we should be able to make the curve have increasing and decreasing segments, so it can intersect the preference curve arbitrarily often.

Specifically, we adopt the specification for the production possibility frontier between consumption and investment that we used previously. Thus, the accumulation equation for $Z$ now takes the form

$$
C_{t}=Y_{t}-Z_{t} \chi\left(\frac{Z_{t+1}-Z_{t}-D_{t}}{Z_{t}}\right) \text {. }
$$

As in the previous specification, $\chi($.$) is a convex cost function. In this$ expression, we have also included a term $D_{t}$ that takes account of any depreciation of the physical capital stock. As in the previous model with complements, the total stock of $Z$ is related to the stock of designs and machines by equation (7) which we repeat here:

$$
Z_{t}=\int_{0}^{A_{t}} x_{t}(i) d i+\int_{0}^{A_{t}} i^{\xi} d i=K_{t}+\int_{0}^{A_{t}}{ }^{\xi}{ }^{\xi} d i
$$

This specification implies that the production function for producing machines and inventions is the same so that there is a linear production possibility frontier between these two types of goods. However, equation (10) tells us that this common production function is different from the production function for making consumption goods. Of course, we could also allow for a nonlinear production possibility frontier between designs and machines. For example, one might want to capture the notion that invention and design work should be more labor intensive and less capital intensive than the production of machines. However, preserving the linear frontier between $A$ and $K$ gives us a major simplification in the structure of the model: this is the crucial assumption that reduces the state variables $K_{t}$ and $A_{t}$ to a single state variable $Z_{t}$. Finally, we assume that physical machines depreciate at the exponential rate $d$ but that design blueprints to not depreciate, so $D_{t}$ can be expressed as $D_{t}=d K_{t}$. In all other respects, the model is the same as the previous model with complementarities.

Figure 3 illustrates one type of simple equilibrium that we have generated using this combined structure. The downward sloping portions of 


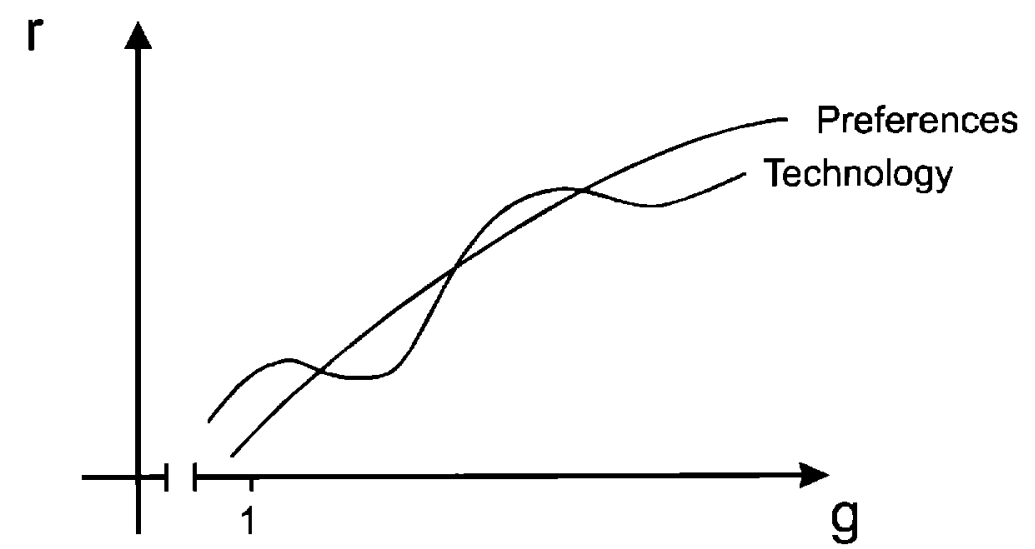

Figure 3: Perfect foresight equilibria with complements and a two-sector technology

the technology curve represent points where the curvature in the production possibility frontier between consumption goods and investment goods is high so its effects overwhelm the effects of complementarity. The upward sloping portions of the technology curve represent regions where the production possibility frontier is relatively flat, so the effects of complementarity dominate. As the analysis in the last section suggests, the middle equilibrium will be unstable under learning. The low and high growth equilibria will be stable under learning.

Table 1 reports values of the growth rate and the interest rate in the high and low growth equilibria in the basic parameterization of the model. (Numerical values for the parameters are given in Appendix A1.) By construction, the interest rates in these two equilibria were arbitrarily set at $4 \%$ and $5 \%$ respectively. The corresponding growth rates for $Z, C$, and $Y$ are $0.2 \%$ per year and $4.9 \%$ per year. The table also reports the values for $p^{z}$, the price of the investment goods relative to consumption goods. In the high growth state, where a larger fraction of GDP is devoted to investment, investment goods are more expensive to produce on the margin, so their 
prices are higher. Even though investment goods are more expensive in the high growth state, a higher level of investment can be sustained because of the positive reinforcing effects that result from the complementarities between the different types of investment goods.

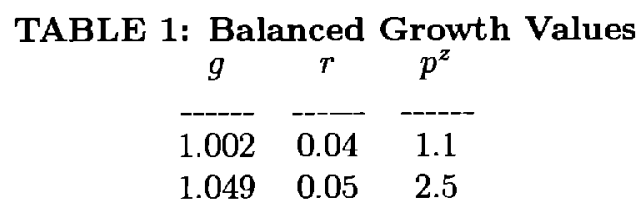

There are a few technical details that we have to address to convince the reader that we have not violated any of the basic rules in the construction of equilibrium models. We mention these briefly here and leave the details for the appendix. First, there is another parameter restriction that we must impose to insure that the maximum feasible growth rate in this economy does not yield infinite discounted utility. We impose this restriction in our specification of the production possibility frontier between investment goods and consumption goods. It implies that there is a maximum feasible rate of growth for $Z$. Beyond this rate, the marginal cost of additional investment becomes infinite. Figure 4 illustrates the nature of the implied production possibility frontier between $Z_{t+1}$ and $C_{t}$ for a given level of $Z_{t}$. The two regions of sharp curvature correspond to the two downward sloping regions of the technology curve in figure 3 . This picture also makes it clear that we are not relying on the any assumptions about short-run increasing returns in the production of new investment goods. Some models generate multiple growth rates by assuming that because of these kinds of short run increasing returns, investment goods are cheaper when a larger fraction of total output is devoted to investment. We generate multiple growth rates despite the fact that investment goods are more expensive when investment is higher and growth is more rapid. We reiterate that the only nonconvexity in the model is the fixed cost associated with invention. All of the work that is done by increasing returns in other models is done here by complementarity.

We have also chosen our parameters so that the rate of growth of $Z$ and (and hence also $A$ ) are positive in both of our perfect foresight equilibria. Thus, without changing the calculated values in our equilibrium, we could 


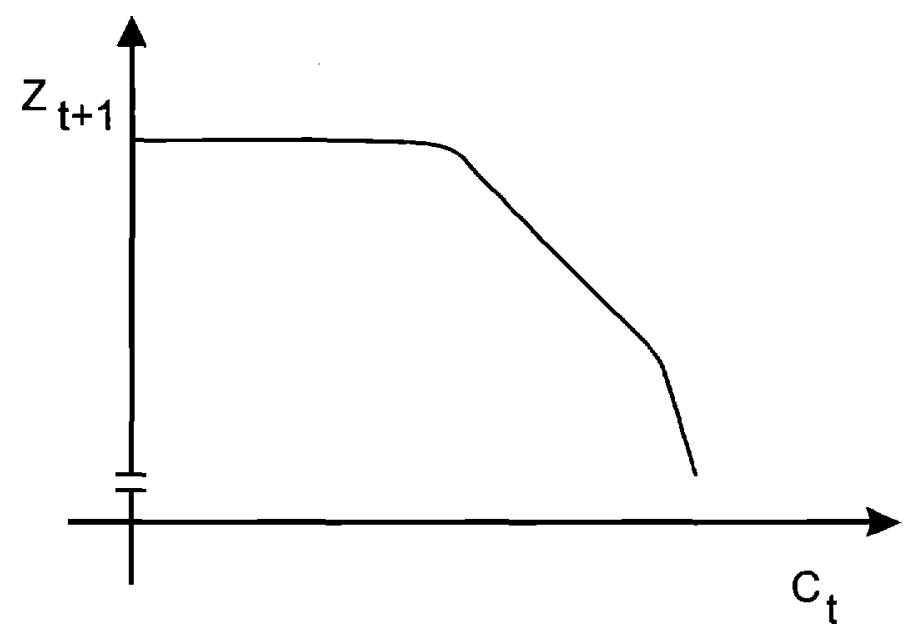

Figure 4: PPF between consumption and next period's stock of total capital

add the restrictions $A_{t+1} \geq A_{t}$ and $K_{t+1} \geq(1-d) K_{t}$, and thereby rule out the possibility that existing designs or machines can be converted into consumption goods or that designs could be converted into machines and vice versa. Likewise, non-negativity of consumption has to be checked. Given our parameter values, this constraint is satisfied.

\section{Growth Cycles with Expectational Indeter- minacy}

\subsection{Equilibrium fluctuations}

So far, we have constructed a model with two stable perfect foresight equilibria. These are building blocks in our complete model of fluctuations between high and low growth states, but by themselves they do not constitute a model of this phenomenon. The figures in Table 1 illustrate why. Suppose that the economy were to change from the high growth state to the 
low growth state. The price $p^{2}$ on each piece of capital would fall from 2.5 to 1.1. In the calculation of the perfect foresight equilibrium, we assumed that this shift could never take place, so consumers make their savings decisions without taking any account of the possibility of this large capital loss on their asset holdings. When consumers make their decisions about how much to consume and save, we must allow them to take account of the switches between high and low growth states that will actually take place in equilibrium.

Formally, we can do this by introducing a random variable that has no effect on preferences or the opportunities that consumers and firms face. "This random variable $s_{t}$ matters only because agents use it to forecast the behavior of the economy. This kind of "extrinsic uncertainty" is susceptible to various interpretations. For a discussion, see for example the chapter on "Market Psychology" in Azariadis (1993). As we suggest in the introduction, we prefer to think of this random variable as something that is under the control of policy makers. In a more complete model, we would let this variable have two effects: a small direct effect on the fundamentals in the economy and a larger indirect effect that acts through its effects on expectations. The small direct effects would explain why agents first began to pay attention to the value of this variable. Nevertheless, to keep our analysis simple and to highlight the expectational effects that it can induce, we assume that the direct effects are negligible

To keep this part of the model as simple as possible, we assume that $s_{t}$ switches randomly between two states with fixed transition probabilities. These transition probabilities will be exogenous parameters in our analysis. In the "high" state firms and households (correctly) anticipate higher investment and more rapid growth during the coming period. However, they also take full account of the probability of a switch to the low growth state in future periods. Formally, we let $s_{t}$ take values from $\{1,2\}$ and assume that it follows a two-state Markov chain with transition probabilities $\Pi_{i j}$ for $i, j=1,2$. These transition probabilities are exogenously given parameters.

Formally, all of the traditional elements in the specification of our model - the preferences and the technology — remain the same after we introduce $s$. All that changes is that in our calculation of an equilibrium, we look for solutions to the equations generated by the model in a larger solution space. In the calculation of perfect foresight equilibria, we did not let consumers or firms make decisions that are contingent on $s$. Now we do. We already 
know that there are equilibria in which consumers choose not to make their choices contingent on $s$ (or equivalently, make the same choices for the two different values of $s$.) These are the perfect foresight equilibria we have already calculated. If we find that there are other equilibria in which output and prices vary with the realization of $s$, we will say that the equilibrium exhibits expectational indeterminacy. This, we think, is a more suggestive description of the behavior in question than the conventional label of a "sunspot equilibrium."

The timing of the realization of $s$ and of decisions is as follows. In period $t-1$, total potential output is realized. Consumers make decisions about how much to consume and how much to invest. Given the net-ofdepreciation stocks of machines $(1-d) K_{t-1}$ and the stock of designs $A_{t-1}$, their decisions about how much to invest will determine the total stock of capital $Z_{t}$ that will be carried over into period $t$. At the beginning of period $t$, the value of $s_{t}$ is realized. Firms then make their decisions about production contingent on the observed value of $s$. In particular, they decide how to split the new investment between additions to $K$ and increases in $A$. When $s$ signals fast growth, firms will allocate more of their investment to increases in $A$ because a design is more valuable when the economy is growing rapidly. Given these decisions by firms, total output will be realized at the end of period $t$. Consumers observe the state $s_{t}$ and decide how much to consume and how much to save. In the high growth and high interest rate state, they will save more and consume less. (This positive response of savings to increases in the interest rate follows from our assumption that the parameter $\sigma$ in the utility function is less than one.) Thus, $Z$ will tend to increase by a larger factor during high growth states. Undepreciated capital and the saving decision of households then determine the quantity of capital $Z_{t+1}$ which is carried into $t+1$ and must once again be divided between increases in $K$ and $A$.

This is the minimal extension of our perfect foresight framework in which we can consider the possibility of expectational indeterminacy - the possibility that the behavior of the economy is determined partly by expectations that are not fully determined by the fundamentals of the economy. This extension nevertheless introduces a substantial degree of additional complexity into the model. In particular, the variable $s_{t}$ introduces a second state variable into the analysis, so it is no longer possible to solve for a single growth rate and interest rate that characterize the equilibria. For any given 
value of the state variable $Z$, there will be two different choices, indexed by $s$, that firms will make regarding additional investment in $K$ and $A$. For any given level of total output, consumers will make two different choices, indexed by $s$, about how much to consume and save. They will be guided by two different interest rates that can also be indexed by $s$. As long as the transition probabilities are positive, decisions in one state will depend on the growth and interest rates that will obtain in the other state, so the state-specific growth rates and interest rates are simultaneously determined. The structure of the model still permits us to reduce the system for the full, infinite dimensional dynamic equilibrium to system with a finite number of equations and unknowns, but it is not a system that can be reduced in any meaningful way to a two-equation, two-variable graphical analysis of the kind that was possible for the perfect foresight equilibria. (The equations for this system are given in the appendix.)

One straightforward way to study the behavior of a system of equations is to look for numerical solutions. We present one such solution that uses the same parameter values and functional forms that we used in calculating the two stable perfect foresight equilibria in Section 2. The only difference here is that we allow for a $5 \%$ probability that between any two periods, the economy switches from the high growth to the low growth state or vice versa. Tables 2 and 3 provide the description of such a growth cycle that we calculated numerically.

TABLE 2: Growth rates in a growth cycle with $\Pi_{11}=\Pi_{22}=0.95$.

$$
\begin{array}{ccc}
\left(s_{t}, s_{t+1}\right)=(i, j) & g_{Z}(i) & g_{A}(i, j) \\
-(1,1) & 1.0083 & - \\
(1.0014 \\
(1,2) & 1.0083 & 1.0053 \\
(2,1) & 1.0437 & 1.0032 \\
(2,2) & 1.0437 & 1.0072
\end{array}
$$


TABLE 3; Other variables in a growth cycle with

$$
\begin{array}{cccc}
\multicolumn{5}{c}{\Pi_{11}=\Pi_{22}=0.95 .} \\
\multicolumn{1}{c}{s_{t}} & r(i) & p^{z}(i) & \frac{C}{Y}(i) \\
-- & --- & - & - \\
\hline i=1 & 0.0383 & 1.435 & 0.978 \\
i=2 & 0.0518 & 1.565 & 0.881
\end{array}
$$

In this equilibrium with expectational indeterminacy, $K$ and $A$ always grow between periods $t$ and $t+1$, regardless of the values taken on by $s_{t}$ and $s_{t+1}$. This means that we do not have to consider the issues that would arise if firms wanted to disinvest. In the two states, the consumptionincome ratio $C / Y$ varies as one would expect given our assumption that savings responds positively to increases in returns. On the firm side, investment behavior would be dominated by firm perceptions about the state of aggregate demand and the rate of growth in the near term. Investment by any individual firm would go up when interest rates are higher and growth is more rapid. Finally, note the relatively small amount of variation in the price of capital goods $p^{z}$ compared to the markedly different values that it takes on in the two different perfect foresight equilibria. This reflects the weight given by forward looking agents to the possibility of a transition between high and low growth states. It also reflects the changes in their behavior that foresight induces.

\subsection{Existence and Stability of Growth Cycles under Learning}

It is no accident that the growth cycle that we calculated numerically generates growth and interest rates that are close to the values that arise in the two perfect foresight equilibria we constructed in Section 2. As we have already noted, the perfect foresight equilibria can be thought of as solutions to the model in which agents do not make their decisions contingent on the value of $s$. It is also possible to interpret them as solutions where decisions do depend on the realization of $s$ but where the transition probabilities between the two states are zero. In this limiting case, the decisions 
that firms and consumers make in the two states can be uncoupled. The problems they face reduce to the problems considered in the perfect foresight analysis. Because the system of equations depends smoothly on the transition probabilities, the implicit function theorem tells us that for transition probabilities near zero, the behavior of the economy in the high or low growth state will be close to the behavior of the economy in the corresponding perfect foresight equilibrium. Quantities and prices will be close to the perfect foresight values. Moreover, as we will show, if the individual perfect foresight equilibria are stable under learning, then the full equilibrium with expectational indeterminacy that switches between states that are near these equilibria will also be stable under learning.

It is easiest to establish both the existence result and the convergence result at the same time. To do so, we must first describe what the learning dynamic is in our full equilibrium with expectational indeterminacy. For the case of perfect foresight, we formulated a model of learning based on a single variable, the expected interest rate. We must now extend this approach to the full model in which variables can depend on $s_{t}$.

The equations that determine the full equilibrium can be interpreted as a mapping that takes a pair of expected interest rates $\left(r_{1}^{e}, r_{2}^{e}\right)$ to a pair of realized interest rates $\left(r_{1}, r_{2}\right)$ :

$$
\left(r_{1}, r_{2}\right)=\tilde{T}\left(r_{1}^{e}, r_{2}^{e}\right)
$$

(The equations themselves are presented in the appendix.) The equilibrium with expectational indeterminacy is a fixed point of this mapping with values $r_{1} \neq r_{2}$. Recall from the previous discussion of learning what the interpretation of this mapping is. If households make savings decisions on the assumption that the interest rates $r_{1}^{e}$, and $r_{2}^{e}$ will prevail in the two states and if producers expect consumers to persist with savings behavior that this induces, then the production side of the market will clear at the interest rates $r_{1}$ and $r_{2}$ in the two different states. That is, $r_{1}$ and $r_{2}$ will be consistent with zero expected profit for an entrant into the invention of new goods. In the hypothetical dynamic determined by the learning process, the time $t$ realized interest rate $r_{t}$ would be given by

$$
r_{t}=\tilde{T}_{i}\left(r_{1, t}^{e}, r_{2, t}^{e}\right) \text { if } s_{t}=i, \text { for } i=1,2,
$$

where $\tilde{T}_{i}$ denotes the $i$ 'th component of the mapping $\tilde{T}$. 
We adopt the following simple state contingent adaptive learning scheme. In state $s$, agents will compare the interest rate they expected to obtain in this state with the interest rate that actually obtains. They will then adjust their expectation of interest rates in this state in the direction of the realized interest rate. As before, the amount of the adjustment depends on the amount of data that they have already collected:

$$
\begin{gathered}
r_{i, t+1}^{e}=r_{i, t}^{e}+\frac{\delta}{N_{i}(t)}\left(r_{t}-r_{i, t}^{e}\right), \text { if } s_{t}=i, \text { and } \\
r_{i, t+1}^{e}=r_{i, t}^{e} \text { if } s_{t} \neq i,
\end{gathered}
$$

In this expression, $N_{i}(t)$ represents the number of times the variable $s_{t}$ has taken value $i$ up until time $t$. Equations (13) and (14) define a dynamic system in the two variables $r_{1}^{e}, r_{2}^{e}$ that is driven by the exogenous stochastic variable $s_{t}$.

An equilibrium growth cycle, i.e., a rational expectations equilibrium with expectational indeterminacy, is a fixed point $\left(r_{1}, r_{2}\right)$ of $(12)$ in which $r_{1} \neq r_{2}$. When we want to be explicit, we can express these equilibrium interest rates as functions of the underlying transition probabilities, $r_{1}(\mathrm{II})$ and $r_{2}(\Pi)$. Let I denote the two-by-two identity matrix. It corresponds to a degenerate transition probability matrix with no changes in the initial state. With this notation, we can describe conditions under which a nondegenerate growth cycle exists and which has the property that for nearby initial conditions, the sequences of state dependent interest rates generated by the learning dynamics converge to the state-dependent interest rates that obtain in equilibrium.

Proposition 1 Suppose that the model outlined in section 2 has two distinct, perfect foresight, balanced growth equilibria. Let the mapping $T$ be as defined in that section, so that the interest rates corresponding to these equilibria satisfy $r_{L}=T\left(r_{L}\right)$ and $r_{H}=T\left(r_{H}\right)$ and assume, without loss of generality, that $r_{L}<r_{H}$. Suppose that these two values both satisfy the perfect foresight stability criterion, $T^{\prime}\left(r_{L}\right)<1$ and $T^{\prime}\left(r_{H}\right)<1$. Then there exists a neighborhood of the identity matrix $\mathbf{I}$ with the property that for any transition probability matrix $\Pi$ in this neighborhood, there is an equilibrium growth cycle $\left(r_{1}(\Pi), r_{2}(\Pi)\right)$ near $\left(r_{L}, r_{H}\right)$ which is locally stable under the learning dynamics (13) and (14).

The proof of the Proposition, together with a precise statement of the phrase "locally stable under learning", is given in the Appendix. 
Finally, we note that we have verified directly that the numerical example presented in the last section is locally stable in the natural sense. If one starts with guesses about the interest rates and growth rates that will obtain in the growth cycle and iterates using the learning dynamic, the resulting values for the interest rates and the growth rates converge to the equilibrium values for the growth cycle. In fact, we used a version of this method to calculate the growth cycle itself.

\section{Discussion of Related Literature}

Models with multiple equilibria are potentially of interest for understanding both macroeconomic fluctuations and economic development. In the development process, we observe substantial diversity of growth rates among countries at similar levels of income. We also observe that the direct foreign investment that flows from advanced countries to poor countries tends to be highly concentrated in a small number of rapidly growing countries. The model that we have developed has an obvious application in this setting, one that is already suggested by Alwyn Young's (1993) model with multiple growth rates. Different countries find themselves in different equilibria. Countries in the high growth, high investment equilibrium attract high levels of foreign investment. The crucial policy steps are those that initiate the transition from the low growth to the high growth equilibrium. These issues deserve a separate treatment and we do not pursue them here. ${ }^{10}$

As indicated in the introduction, there are many strands in the literature on aggregate models with some form of indeterminacy or multiplicity of equilibria. We now review how the model of this paper fits into this extensive literature.

One strand (surveyed in Guesnerie and Woodford 1992) focuses on the possibility of endogenous fluctuations in dynamic economies such as overlapping generations models. Another strand has stressed complementarities in the decision making of different agents that arise from externalities or imperfect competition. These complementarities can lead to multiple equi-

\footnotetext{
${ }^{10}$ See the survey by Matsuyama (1995) for a discussion of the relevance of models with multiple equilibria and multiple steady states to the development experience. Benhabib and Gali (1995) also use these kinds of models to characterize the behavior of different developing countries.
} 
libria, sometimes even to a continuum of equilibria. Recent surveys include Matsuyama (1995) and Silvestre (1993). Many of these models do not, however, explicitly construct rational expectations models with endogenous fluctuations arising from expectational indeterminacy. A new strand, discussed below, emphasizes the possibility of multiple equilibria in models of growth.

Our model is not closely related to models derived from Brock (1975) that hinge on the special properties of fiat money; nor to models that follow Calvo (1978) or Cass and Shell (1983) and allow for overlapping generations of agents; nor to models in the tradition of Diamond (1982) that depend on search externalities in the labor market; nor to models such as Woodford (1991) that depend on special aspects of imperfect competition. As macroeconomists, we are not convinced that the mechanisms identified in these papers are plausible mechanisms for generating expectational indeterminacy in real economies. However, as economic theorists, we have been able to take advantage of the insights that have developed in the exploration of these models. To cite just one example, our analysis of stability under learning builds on results developed by Howitt and McAfee (1992) in the context of a model with search externalities in the labor market.

In the early literature, our model is most closely related to two papers. One, by Andrei Shleifer (1986), examines a model in which innovation is motivated by monopoly profit. The second paper, by John Bryant (1983), allows for a strong from of complementarity between a large number of intermediate inputs in production. Our model can be thought of as an explicit dynamic extension that incorporates elements from both of these models. More recent work on complementarities and imperfect competition has been formulated either using models with unique equilibria with large multipliers, e.g. Chatterjee and Cooper (1993), or models with expectational indeterminacy, e.g. Chatterjee, Cooper, and Ravikumar (1993). The formal methods used in these papers are different, but the substantive economic assumptions are qualitatively the same. We have chosen the latter approach because it locates the explanation for economic fluctuations squarely on expectations.

The unexpected discovery that growth models sometimes exhibit various forms of indeterminacy or multiplicity of equilibria lent new impetus to work on these issues. ${ }^{11}$ Like these papers, our model has its origins in a

\footnotetext{
${ }^{11}$ For recent work in this area, see Benhabib and Farmer (1994), Benhabib and Perli
} 
model of long-run growth, but there is a fundamental difference. Many of the other approaches based on models of growth generate the underlying multiplicity of equilibria by demonstrating the existence of a continuum of perfect foresight equilibria. Typically, this is done by linearizing a model around a single steady state that can be approached along an infinite number of paths. In contrast, our underlying growth model has strong nonlinearities resulting in a finite number of distinct balanced growth paths with perfect foresight.

Models with a continuum of equilibria approaching a single steady state can offer a novel strategy for justifying the stickiness of prices and the power of monetary policy. If there exists a continuum of equilibrium prices and quantities, a natural focal equilibrium at any point in time is one that makes prices today equal to prices yesterday. (See Farmer 1991, and Beaudry and Devereux 1993 for models of this type.) However, a potential difficulty with solutions in the neighborhood of an indeterminate steady state is that they may not to be robust under learning. For example, in the simplest model in this genre (the overlapping generations model with money) Lucas (1986) found that adaptive learning schemes selected the determinate rather than the indeterminate steady state. Evans and Honkapohja (1994) confirm this lack of robustness for a somewhat more general class of models.

Another type of indeterminacy in growth models, described in the survey by Benhabib and Gali (1995), results from the presence of a finite number of distinct steady states. ${ }^{12}$ For some initial values of the state variables in these models, there may be a finite number of discrete equilibrium paths, each of which leads to a distinct steady state. In contrast to our model, these models have steady states in levels of per capita income that grow at

(1994), Chamley (1993), Farmer and Guo (1994), Gali (1994), and Xie (1994). For general discussions see Kehoe, Levine and Romer (1992), Benhabib and Rustichini (1994), and Benhabib and Gali (1995). The economic assumptions required for local indeterminacy are in some cases possibly extreme. For example, Benhabib and Farmer (1994) and Farmer and Guo (1994) require increasing marginal returns to labor. (See Schmitt-Grohé 1995 for a discussion of the assumptions required in various models.) In other cases the fit with the data is poor in dimensions we regard as crucial. For example Gali (1994) obtains expectational indeterminacy only when the procyclicality of the investment share is weak.

${ }^{12}$ These can arise, for example, because of threshold effects as in Azariadis and Drazen (1990), or because of various kinds of increasing returns. Again, see the discussion in Matsuyama (1995). 
the same steady state growth rate or which do not grow at all.

Our approach is similar in the sense that we start from an underlying model with a finite number of distinct equilibria rather than a continuum of equilibria. However, in our case, these distinct equilibria have different growth rates rather than different steady state levels. Starting from any initial condition, fast growth and slow growth are possible. Like Startz (1994), we adopt this approach because of empirical work showing that a two-state model with a high growth and a low growth state gives a reasonably good description of the variation in US economic growth (Hamilton, 1989). Drugeon and Wigniolle (1996) have also developed a model of endogenous growth with Markovian fluctuations in growth rates, but they, like Startz, rely on the assumption of positive technological externalities which we have worked hard to avoid.

To sum up this discussion, at a formal level our model exhibits multiple distinct balanced growth paths. We show that simple learning rules in this setting can lead to solutions exhibiting expectational indeterminacy, with economic growth switching stochastically between high and low rates. The crucial economic assumptions in our growth model are those we regard as the most plausible: fixed costs in R\&D and complementarities between capital goods. These elements yield a model of economic fluctuations driven by self-fulfilling shifts in investment expectations, and taking the form we regard as most plausible: the strength of business confidence depends on short and medium term forecasts of the rate at which future sales and profits are expected to expand.

\section{Conclusions}

The fundamental challenge for macroeconomists is to identify mechanisms that can amplify small shocks to produce large, coordinated aggregate fluctuations. Some kind of amplification is necessary, for if the shocks were as large as the fluctuations themselves, they would be obvious for all to see. The difficulty that economists have had in identifying and agreeing on these shocks suggests that they are not large and obvious.

The real business cycle literature focuses on shocks to the technology. Existing models generally do not have large multipliers, and no one has been able to provide any direct evidence for technology shocks with the required 
amplitude and persistence. The absence of candidate shocks is particularly clear in the context of the Great Depression of the 1930s. So far as we know, no real business cycle theorist has proposed that events during this decade represent Pareto optimal adjustments to exogenous technology shocks. The alternative new Keynesian position (once known as the Monetarist position) holds that nominal prices do not adjust, so that monetary disturbances are translated into real disturbances. ${ }^{13}$ Ever since Friedman and Schwartz published A Monetary History of the United States (1963), the evidence implicating monetary disturbances during the 1930s has been the foundation for a widespread belief in the power of monetary policy. Even so, the depression poses a challenge for the sticky-price interpretation of economic fluctuations that is almost as serious as the one it poses for real business cycle theorists. None of the existing explanations for the stickiness of prices seem capable of explaining the extraordinary persistence of the downturn experienced during that decade.

For us, expectational indeterminancy offers a means to provide a precise, microeconomic foundation for the amplification of shocks and a way to explain the persistence of low growth states. To keep the discussion specific, we treat the shocks that initiate the switches between boom and bust as monetary shocks, but nothing in our treatment depends on this interpretation. One could equally well assume that the underlying shocks are shocks to the technology or external shocks that impinge from the rest of the world. The key point is that a model based on expectational indeterminacy is consistent with a variety of interpretations about the underlying sources of shocks.

Our formulation has made several carefully chosen simplifying assumptions. In general, a rational expectations equilibrium in a dynamic model is a fixed point in an infinite dimensional space. The equilibrium we calculate specifies prices and quantities for every date $t$ and for every history of realizations of the random policy variable from date 0 up to date $t$. Because of the special structure that we impose on our model, this very difficult infinite dimensional fixed point problem can be reduced to a relatively tractable system with a small number of equations and unknowns. This simplification is possible because the underlying growth model does not have any transition dynamics. In a perfect foresight equilibrium, the dynamic behavior at every

\footnotetext{
${ }^{13}$ See Ball and Mankiw (1994) for a recent statement of this position.
} 
date, can be summarized by a single number, the rate of growth of output. This number is independent of the history leading up to this date. Several different perfect foresight equilibria can be summarized by a growth rate that is specific to each. This very special property arises because a combination of simplifying assumptions. The first is that there is only one state variable in the model, the stock of total capital $Z$. Different values of $Z$ change the effective size of the economy, but because the technology is scale independent, choices at every date are merely scaled up versions of choices at every other date. The second assumption is that output grows linearly with $Z$. The third is that utility takes the usual, constant elasticity form.

Any departure from these assumptions will make it impossible to reduce the characterization of an equilibrium to a finite set of equations and unknowns. This means that any exploration of the theoretical issues raised here is very tightly constrained by technical feasibility, and constrained in ways that have important substantive implications. One of the most important restrictions comes on the preference side of the model. For an investment boom to be self-sustaining, higher rates of return on investment must induce a larger quantity of investment. To achieve this with constant elasticity preferences $u(C)=\frac{1}{1-\sigma} c^{1-\sigma}$, we must choose a value of $\sigma \in(0,1)$. We know from other kinds of evidence that this entire family of preferences cannot simultaneously give a good description of the intertemporal elasticity substitution and attitudes toward risk and that even within this family a value of $\sigma$ in this range may not be particularly plausible. There are a variety of plausible extensions of the preference side of the model that can lead to the required result - that investment increases as a fraction of output during a boom. However, it will be a challenge to craft a model that incorporates these extensions and still is tractable.

The other obvious compromise with tractability in the model comes in a specification that forces all investment goods to be complements with each other. A more realistic specification would allow for clusters of goods to be complements with each other and that lets different clusters act as substitutes. Typewriters, carbon paper, and correction fluid are complements. So are laser printers, personal computers, and word processors. These two clusters of goods are substitutes for each other. In this kind of world, we suspect that the forces we derive from the presence of complementarities would be even stronger than they are in the current model. What complementarity does in the model is influence the timing of investment decisions. 
The preferred time to introduce a good is when its complementary goods are being introduced. The incentive to group these investment decisions will be even stronger if the expected lifetime of a given cluster of goods is likely to be cut short by the introduction of some cluster of substitutes that will soon replace them. In this direction as well, we believe that there are natural extensions of our model, but they may not lead to the kind of simple analysis of expectational indeterminacy that we have been able to conduct.

Given the compromises that are forced upon us by our desire to be rigorous and explicit in our analysis, it is not a simple or straightforward matter to gauge the empirical plausibility of the process we describe. The correct place to start, it seems to us, is with the basic presumptions that drive everything else. The first is that aggregate investment can increase sharply in response to perceptions of increased opportunity. The second is that the time to invest is precisely when others are investing. More structures raise the returns to investment in equipment and furnishings. Better computer hardware raises the return on investment in new computer software and vice versa. The time to buy may be precisely when everyone else is buying and questions about standards have at least temporarily been resolved.

Evaluating the evidence on these kinds of interaction effects and their influence on the timing of investment decisions may be fairly complicated. In particular, it may require more disaggregation that is typical for most types of investment goods. The timing issues that a manufacturer faces in upgrading the hardware and software that run computer controlled machine tools may be at least as complicated as the timing decisions that someone operating a desktop computer faces in deciding whether to upgrade an operating system, but nothing in the aggregate equipment investment figures is likely to signal the importance of this kind of effect.

The kind of theoretical exercise undertaken here does not prove anything about the quantitative importance of complementarity or market power. All it can do is demonstrate that it is possible that these effects lead to selffulfilling expectational booms and busts. Once this is established, we may be encouraged to look at the data from a slightly different perspective. When we do, we may find that there is some basis for this old conjecture that changes in expectations are the major sources of fluctuations in aggregate investment spending. 


\section{A Appendix}

\section{A.1 Characterizing the perfect foresight equilibria}

We will derive the general expression for the no-arbitrage condition depicted in Figure 3. The monotonically increasing version depicted in Figure 2 emerges as a special case.

Final goods producers are price takers in the market for capital goods. In equilibrium they equate the rental rate with the marginal product of capital

$$
R_{t}(j)=\frac{\partial Y}{\partial x_{t}(j)}=L^{1-\alpha}\left(\int_{0}^{A_{t}} x_{t}(i)^{\gamma} d i\right)^{\phi-1} \phi \gamma x_{t}(j)^{\gamma-1}
$$

The firms that supply capital goods act as monopolistic competitors. Formally, they purchase general purpose capital $Z$ and convert it into specialized types of capital goods at the rate of one unit of general purpose capital for one unit of specialized differentiated capital. Our timing convention implies that production is realized at the end of a period. At the end of period $t$, a capital-goods supplier will earn revenue $R_{t}(j) x_{t}(j)$. In the beginning of period $t$, it takes $x_{t}(j)$ units of $Z$ to produce the $x_{t}(j)$ units of capital of type $j$ that this firm owns and rents out. The rental cost on these units of $Z$ is $r_{t} x_{t}(j) p_{t}^{z}$, where $p_{t}^{z}$ is the price in units of consumption of one unit of $Z$. A fraction $d$ of the capital goods depreciates in period $t$, so the total cost to the capital goods supplier in period $t$ is $\left(r_{t}+d\right) x_{t}(j) p_{t}^{z}$. This firm selects its output to maximize profits, taking as given the inverse demand curve for the rental price in equation (15) and the price $p^{z}$. This leads to the mark-up rule

$$
R_{t}(j)=\left(r_{t}+d\right) p_{t}^{z} / \gamma \equiv R\left(r_{t}, p_{t}^{z}\right)
$$

Since this holds for each intermediate good $j$ we have, by symmetry, that the provision of intermediate goods is at the same level for all types $j$ and we denote its common value at time $t$ by $x_{t}(j)=x_{t}$. It follows that aggregate output at time $t$ is given by

$$
Y_{t}=L^{1-\alpha}\left(x_{t}^{\gamma} A_{t}\right)^{\phi}
$$


where

$$
x_{t}=L A_{t}^{\frac{\phi-1}{1-\alpha}}\left[\frac{R_{t}}{\phi \gamma}\right]^{\frac{-1}{1-\alpha}}
$$

with $R_{t}$ given by (16).

The mark-up pricing rule implies that the quantity of each type of intermediate good is a function of $A_{t}, p^{z}$ and $r$. By substitution it follows that profits (at the end of period $t$ ) for each type of intermediate good are given by

$$
\pi_{t}=R_{t} x_{t}-\left(r_{t}+d\right) p_{t}^{z} x_{t}=(1-\gamma) R_{t} x_{t}=\Omega A_{t}^{\frac{\phi-1}{1-\alpha}}\left(\left(r_{t}+d\right) p_{t}^{z}\right)^{\alpha /(\alpha-1)},
$$

where $\Omega=\phi^{1 /(1-\alpha)}(1-\gamma) \gamma^{\frac{1+\alpha}{1-\alpha}} L$.

To produce a particular type of intermediate good $j$, a firm must first incur the cost of inventing and designing this good. Recall that the cost of a new invention for good $j$ is $j^{\xi}$ units of investment goods $Z$ where $\xi>0$. Because the firms are monopolistic competitors, at each time $t$ the quantity of designs is determined by a zero profit condition which states that the fixed cost of the last design created at time $t$ must be just equal to the present discounted value of the stream of monopoly rents it offers. In a perfect foresight equilibrium with balanced growth, the interest rate is constant and the required zero profit condition for the marginal good invented at time $t$ (which will have an index $j=A_{t}$ ) is given by

$$
p_{t}^{z} A_{t}^{\xi}=\sum_{s=0}^{\infty} \pi_{t+s}(1+r)^{-(s+1)}
$$

This expression for discounted profits reflects our assumption that the cost of inventing a good is incurred at the start of period $t$ but the first profit is not realized until the end of the period, and hence is discounted back to the beginning of the period by a factor $(1+r)^{-1}$. Under the assumption of balanced growth, the rate of growth of designs $A_{t+1} / A_{t}=g_{A}$ will be constant. Substituting (19) into this sum gives

$$
p^{z} A_{t}^{\xi}=A_{t}^{\frac{\phi-1}{1-\alpha}} \Omega\left((r+d) p^{z}\right)^{-\alpha /(1-\alpha)} \sum_{s=0}^{\infty}\left(g_{A}^{\xi}\right)^{s}(1+r)^{-(s+1)} .
$$


Because we assume that $\xi=\frac{\phi-1}{1-\alpha}$, we can cancel $A_{t}^{\xi}$ and sum the series to obtain the zero profit condition

$$
g_{A}^{\xi}=1+r-\Omega\left(p^{z}\right)^{-1 /(1-\alpha)}(r+d)^{-\alpha /(1-\alpha)} .
$$

Gross investment is equal to the net increase in $Z$ minus a correction for the depreciation of physical capital goods. Let $\eta$ represent the fraction of $Z$ that is allocated to physical capital goods. We will derive an expression for $\eta$ in what follows. Production of general purpose capital $Z$ takes place in a competitive sector, so that the price of capital goods in terms of consumption is

$$
p^{z}=-\frac{d C_{t}}{d Z_{t+1}}=\chi^{\prime}\left(\frac{Z_{t+1}}{Z_{t}}-1+d \eta_{t}\right)
$$

(Recall that the function $\chi($.$) specified in (10) gives the tradeoff between$ consumption and $Z$ ).

At any date $t$, the following relationship must hold between $Z, x$, and $A$ :

$$
Z_{t}=x_{t} A_{t}+\int_{0}^{A_{t}}{ }_{i}^{\xi} d i=x_{t} A_{t}+\frac{A_{t}^{1+\xi}}{1+\xi} .
$$

Along a balanced growth path, the output-capital ratio $Y / Z$, the growth rate of capital, the interest rate and $p^{2}$ are constant. Using (18) to substitute for $x_{t}$, one obtains an expression for $Z_{t}$ in terms of $A_{t}$ :

$$
Z_{t}=A_{t}^{1+\xi}\left\{(1+\xi)^{-1}+L\left[\frac{R_{t}}{\phi \gamma}\right]^{\frac{1}{\alpha-1}}\right\} \equiv A_{t}^{1+\xi} \mu\left(R_{t}\right)
$$

Note that we have defined a function $\mu(R)$ as a shorthand expression for the term in braces in this equation. Since $\eta_{t}=A_{t} x_{t} / Z_{t}$, it follows from (21) and (22) that

$$
\eta\left(R_{t}\right)=1-\frac{1}{(1+\xi) \mu\left(R_{t}\right)} .
$$

Thus we can express the price of general purpose capital as

$$
p^{z}=\chi^{\prime}\left(g_{Z}-1+d \eta\left(R\left(r, p^{z}\right)\right)\right) .
$$


Finally, from the above expression (22) for $Z_{t}$ it follows that $g_{Z}=g_{A}^{1+\xi}$. Substituting in the expression (20) for $g_{A}$ and using $\xi=\frac{\phi-1}{1-\alpha}$ we have

$$
g_{Z}=\left[1+r-\Omega\left(p^{z}\right)^{-1 /(1-\alpha)}(r+d)^{-\alpha /(1-\alpha)}\right]^{\frac{\phi-\alpha}{\phi-1}} .
$$

Together, equations (23) and (24) give an implicit definition of the locus of pairs $(g, r)$ that are consistent with the zero profit condition. In the special case where $\chi$ is the identity, $p^{z}$ is a constant that can be taken to be equal to 1 and equation (24) alone determines this locus. These loci are the "technology" curves in Figures 2 and 3.

To complete the analysis of the perfect foresight equilibrium, it remains to verify that consumption and the stock of $Z$ grow at the same rate. Note first that if we substitute (18) into (17), this generates an expression for $Y_{t}$ in terms of $A_{t}$. Using the expression for $Z$ in terms of $A$ from equation (22), it follows that the ratio of output to total capital is constant along a balanced growth path:

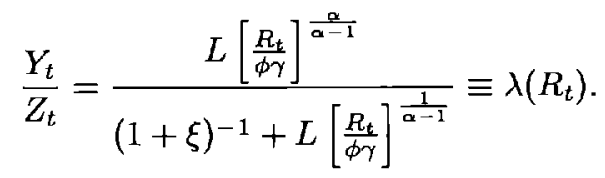

Next, we solve for the optimal pattern of consumption by the method of undetermined coefficients. We guess that consumption takes the form $C_{t}=\theta Z_{t}$ and solve for $\theta$. Using the first order condition for the consumer's maximization problem, it follows that

$$
g_{Z}=[\beta(1+r)]^{\frac{1}{\sigma}} .
$$

Finally, we note that we can use equation (10) to conclude that

$$
\theta\left(r, p^{z}\right)=\lambda\left(R\left(r, p^{z}\right)\right)-\chi\left\{[\beta(1+r)]^{1 / \sigma}-1+d \eta\left(R\left(r, p^{z}\right)\right)\right\} .
$$

Provided one can show that $g_{Z}<1+r$, the transversality condition at infinity for the consumer's maximization problem will also be satisfied. This implies that the conjectured solution for consumption satisfies the sufficient conditions for optimality. 
It remains for us to specify the parameters we used in the calculation of our numerical example and the precise form we selected for the function $\chi$. In the calculation of the two stable perfect foresight equilibria, we used the following parameter values: $\alpha=0.4, \Omega=.015, \phi=4, d=0.15, \beta=$ $.962, \sigma=0.21, L=0.356244889$.

A continuous, piecewise linear form $\tilde{\chi}$ underlying the $\chi$ function was constructed as follows: $\bar{\chi}(0)=0, \tilde{\chi}^{\prime}(y)=p_{0}$ for $y<y_{1}, \tilde{\chi}^{\prime}(y)=p_{1}$ for $y_{1} \leq y \leq y_{2}$, and $\tilde{\chi}^{\prime}(y)=p_{2}$ for $y>y_{2}$. The smoothed function sets $\chi(y)=\tilde{\chi}(y)$ for $y \leq y_{1}-\delta_{1}, y_{1}+\delta_{1}<y \leq y_{2}-\delta_{2}$, and $y>y_{2}+$ $\delta_{2}$. In the interval $\left(y_{1}-\delta_{1}, y_{1}+\delta_{1}\right] \chi(y)$ is the quadratic which satisfies $\chi\left(y_{1}-\delta_{1}\right)=\tilde{\chi}\left(y_{1}-\delta_{1}\right), \chi^{\prime}\left(y_{1}-\delta_{1}\right)=\tilde{\chi}^{\prime}\left(y_{1}-\delta_{1}\right)$. Similarly, in the interval $\left(y_{2}-\delta_{2}, y_{2}+\delta_{2}\right] \chi(y)$ is another quadratic satisfying $\chi\left(y_{2}-\delta_{2}\right)=\tilde{\chi}\left(y_{2}-\right.$ $\left.\delta_{2}\right), \chi^{\prime}\left(y_{2}-\delta_{2}\right)=\tilde{\chi}^{\prime}\left(y_{2}-\delta_{2}\right)$. For the numerical example we selected the values $p_{0}=0.555406, p_{1}=1.46523, p_{2}=5.06686, y_{1}=0.0199733, y_{2}=$ $0.0535351, \delta_{1}=.001, \delta_{2}=.0005$.

Finally, we must verify that discounted utility is finite along all feasible growth paths and that the transversality condition at infinity is satisfied for the consumer. To establish both of these results, it is sufficient to show that the maximum feasible rate of growth satisfies $g_{\max }^{1-\sigma}<\frac{1}{\beta}$. To do this, we impose an additional constraint on the function $\chi$ which limits the maximum feasible rate of growth of $Z$. Specifically, we assume that $\chi^{\prime}(y)$ goes to infinity for values of $y$ above a threshold $y_{\max }$. In our numerical example, the high growth rate for $Z$ satisfies the inequality $g_{z}<\frac{1}{1+\tau}=\beta g_{z}^{-\sigma}$, so we know that we can pick a value of $y_{\max }$ that is strictly larger than the value of $y$ that obtains in the high growth state. It follows that the imposition of this upper bound will not change the values of the perfect foresight equilibria that we have calculated without imposing this bound, so we are free to impose it after the fact without redoing our numerical calculations.

\section{A.2 Characterizing the equilibria with expectational indeterminacy}

Once we introduce the random variable $s$, both households and firms face uncertainty about the state of the world in the subsequent period. We must therefore introduce state contingent prices for output. Let $q\left(s_{t}, s_{t+1}\right)$ denote the price at the end of time $t$ of one unit of output available at the beginning of period $t+1$, contingent on the realization of $s_{t+1}$. Thus $q\left(s_{t}, s_{t+1}\right)$ prices 
only the uncertainty associated with the realization of $s_{t+1}$. Formally, we assume that no clock time elapses during this interval. The pricing of goods over time is associated with a state contingent interest rate $r\left(s_{t}\right)$ which denotes the sure net 1-period interest rate on consumption good loans over the interval extending from the beginning of period $t$ to the end of period $t$. Thus the $q$ 's price only the uncertainty and $r$ 's prices only the time lag. Since one unit of output in state $s_{t}$ at the end of period $t$ necessarily is one unit of output in either state 1 or 2 at the beginning of period $t+1$, we have the basic arbitrage formulas

$$
q(i, 1)+q(i, 2)=1 \text { for } i=1,2 .
$$

We need to restate all of the equations for the consumer and firms in terms that allow for the uncertainty associated with $s$. We begin with the arbitrage relationship for firms. The problem for the producer of the final good continues to be a static, one period problem, so we can write $R_{t}(j)=\frac{\partial Y}{\partial x_{t}(j)}$ just as we did before. This producer considers only the rental cost $R_{t}$ of the specialized capital goods that it uses. In contrast, the firms that produce, own, and rent out these specialized capital goods now must worry about capital gains or losses on their goods that may be induced by changes in the price of general purpose capital, $p^{z}$. When the economy switches to a slow growth equilibrium, the rate of investment falls. This makes the cost of new capital goods fall, which makes the value of all existing capital goods fall. We can price the uncertainty facing the producer of a specialized type of capital using $q\left(s_{i}, s_{t+1}\right)$ and the price $p^{z}$. End-ofperiod profits for the firm supplying the specialized intermediate capital good $j$ are

$$
\begin{aligned}
& {\left[R_{t}(j)\left(s_{t}\right) x_{t}(j)+(1-d) p^{z}(1) x_{t}(j)\right] q\left(s_{t}, 1\right)+} \\
& {\left[R_{t}(j)\left(s_{t}\right) x_{t}(j)+(1-d) p^{z}(2) x_{t}(j)\right] q\left(s_{t}, 2\right)-\left(1+r\left(s_{t}\right)\right) p^{z}\left(s_{t}\right) x_{t}(j)}
\end{aligned}
$$

Maximizing profits then leads to the equation

$$
R\left(s_{t}\right)=\gamma^{-1}\left[\left(1+r\left(s_{t}\right)\right) p^{z}\left(s_{t}\right)-(1-d)\left(p^{z}(1) q\left(s_{t}, 1\right)+p^{z}(2) q\left(s_{t}, 2\right)\right)\right]
$$

for $s_{t}=1,2$. As before, $R_{t}(j)=R_{t}$ and $x_{t}(j)=x_{t}$ turn out not to depend on $j$ and $(18)$ becomes $x_{t}\left(s_{t}\right)=L A_{t}^{\frac{\phi-1}{1-\alpha}}\left[\frac{R_{t}\left(s_{t}\right)}{\phi \gamma}\right]^{\frac{-1}{1-\alpha}}$. 
It is convenient to introduce the notation

$$
\hat{p}^{z}\left(s_{t}\right)=p^{z}(1) q\left(s_{t}, 1\right)+p^{z}(2) q\left(s_{t}, 2\right) \text { for } s_{t}=1,2
$$

for the "expected" price of capital. End-of-period profits are given by

$\pi_{t}=L A_{t}^{\frac{\phi-1}{1-\alpha}}\left[\phi \gamma\left(\frac{R\left(s_{t}\right)}{\phi \gamma}\right)^{\frac{\alpha}{\alpha-1}}+\left(\frac{R\left(s_{t}\right)}{\phi \gamma}\right)^{\frac{1}{\alpha-1}}\left[(1-d) \hat{p}^{z}\left(s_{t}\right)-\left(1+r\left(s_{t}\right)\right) p^{z}\left(s_{t}\right)\right]\right]$.

This leads us to define the profit function as

$$
\pi\left(s_{t}, A_{t}\right)=A_{t}^{\frac{\phi-1}{1-\alpha}} \Gamma\left(R\left(s_{t}\right), \hat{p}^{z}\left(s_{t}\right), r\left(s_{t}\right), p^{z}\left(s_{t}\right)\right),
$$

where

$$
\Gamma\left(R, \hat{p}^{z}, r, p^{z}\right) \equiv L\left[\phi \gamma\left(\frac{R}{\phi \gamma}\right)^{\frac{\alpha}{\alpha-1}}+\left(\frac{R}{\phi \gamma}\right)^{\frac{1}{\alpha-1}}\left[(1-d) \hat{p}^{z}-(1+r) p^{z}\right]\right] .
$$

Note that the equation for the rental rate can be rewritten

$$
R\left(s_{t}\right)=\gamma^{-1}\left[\left(1+r\left(s_{t}\right)\right) p^{z}\left(s_{t}\right)-(1-d) \hat{p}^{z}\left(s_{t}\right)\right] \text { for } s_{t}=1,2 .
$$

The decisions to introduce designs are also dynamic and made under uncertainty. It is most convenient to approach the problem in terms of asset pricing. Let $P\left(s_{t}, A_{t}\right)$ denote the price of one unit of designs in period $t$ contingent on the state $s_{t}$ and the aggregate quantity of designs $A_{t}$. After they have been introduced, all designs are equivalent, so we can use a single price for all of them. Since each unit of design capital yields current profits $\pi\left(s_{t}, A_{t}\right)$, we have the arbitrage (or zero profit) condition

$$
P\left(s_{t}, A_{t}\right)=\frac{q\left(s_{t}, 1\right)}{1+r\left(s_{t}\right)}\left(\pi\left(s_{t}, A_{t}\right)+P\left(1, A_{t+1}\right)\right)+\frac{q\left(s_{t}, 2\right)}{1+r\left(s_{t}\right)}\left(\pi\left(s_{t}, A_{t}\right)+P\left(2, A_{t+1}\right)\right) .
$$

At every date, the price of a unit of design capital is determined by the cost of producing the last design,

$$
P\left(s_{t}, A_{t}\right)=A_{t}^{\xi} p^{z}\left(s_{t}\right)
$$


Writing $g_{A}\left(s_{t}, s_{t+1}\right)=A_{t+1}\left(s_{t+1}\right) / A_{t}\left(s_{t}\right)$ for the rate of growth of design capital and combining the above equations we obtain the equations:

$$
\begin{aligned}
p^{z}(i)= & (1+r(i))^{-1}\left[\Gamma\left(R(i), \hat{p}^{z}(i), r(i), p^{z}(i)\right)\right]+ \\
& (1+r(i))^{-1}\left[q(i, 1) p^{z}(1) g_{A}(i, 1)^{\xi}+q(i, 2) p^{z}(2) g_{A}(i, 2)^{\xi}\right]
\end{aligned}
$$

for $i=1,2$.

We look for a solution in which $\theta$ and $g_{Z}$ are functions of the current state $i$ of $s_{t}$. The ratio of total investment to investment in designs is given by

$$
(1+\xi)\left(Z_{t} / A_{t}^{1+\xi}\right)\left(s_{t}\right)=(1+\xi) \mu\left(R\left(s_{t}\right)\right)
$$

where $\mu$ is defined by equation (22). From the preceding equation the 4 possible growth rates $\frac{A_{t+1}}{A_{t}}=g_{A}\left(s_{t}, s_{t+1}\right)$ are related to capital growth by

$$
g_{A}(i, j)=\left(g_{Z}(i) \frac{\mu(R(i))}{\mu(R(j))}\right)^{(1+\xi)^{-1}}, \text { for } i, j=1,2
$$

Turning to the household, there are now Euler equations for the two state contingent assets which pay one unit of consumption at $t+1$ in a specified state. For expected state contingent interest rates $r^{e}\left(s_{t+1}\right)$ these first-order equations are

$$
q\left(s_{t}, s_{t+1}\right)\left[\frac{C_{t+1}}{C_{t}}\left(s_{t}, s_{t+1}\right)\right]^{\sigma}=\beta \Pi\left(s_{t}, s_{t+1}\right)\left(1+r^{e}\left(s_{t+1}\right)\right)
$$

Here $\Pi\left(s_{t}, s_{t+1}\right)$ is the transition probability from state $s_{t}$ to $s_{t+1}$. We will also use the notation $\Pi_{i j}=\Pi(i, j), i, j=1,2$. The optimal solution for the household allows its consumption to capital ratio to depend on the state $s_{t}$ :

$$
\left(C_{t} / Z_{t}\right)\left(s_{t}\right)=\theta\left(s_{t}\right)
$$

Combining these last two equations yields

$$
\beta \Pi_{i j}\left(1+r^{e}(j)\right)=q(i, j)\left[\frac{\theta(j)}{\theta(i)} g_{Z}(i)\right]^{\sigma} \text { for } i, j=1,2 .
$$

Additional restrictions on the values of $\theta(i)$ come from the product transformation function (10) which holds state by state. Thus we have a statecontingent version of equation (27):

$$
\theta(i)=\lambda(R(i))-\chi\left[g_{Z}(i)-1+d \eta(R(i))\right] \text { for } i=1,2 .
$$


Finally, we also have the state contingent version of the capital price equation (23)

$$
\hat{p}^{z}(i)=\chi^{\prime}\left(g_{Z}(i)-1+d \eta(R(i))\right) \text { for } i=1,2,
$$

and the rational expectations condition

$$
r(i)=r^{e}(i) \text { for } i=1,2 .
$$

The equations (28), (29), (30), (31), (32), (33), (34), (35) and (36) form a system of 22 nonlinear equations in the 22 unknowns $r(i), r^{e}(i), R(i), q(i, j)$, $\theta(i), p^{z}(i), \hat{p}^{z}(i), g_{A}(i, j)$, and $g_{Z}(i)$. These characterize an equilibrium with expectational indeterminacy. Together, they implicitly determine the mapping $(r(1), r(2))=\bar{T}\left(r^{e}(1), r^{e}(2)\right)$ described in the main text.

\section{.3 Existence and Stability of Growth Cycles}

For notational convenience write $r_{i}=r(i)$ and $r_{i}^{e}=r^{e}(i)$ for $i=1,2$. We now sketch the proof of the proposition given in the text and show that generically there exist growth cycles for probabilities in a neighborhood of the identity matrix when there are distinct perfect foresight balanced growth paths. Let $r_{L}, r_{H}$ denote the interest rates for two distinct balanced growth paths. By assumption $r_{L} \neq r_{H}$. Define a new function

$$
W\left(\left(r_{1}, r_{2}\right),\left(\Pi_{11}, \Pi_{22}\right)\right) \equiv \tilde{T}\left(\left(r_{1}, r_{2}\right),\left(\Pi_{11}, \Pi_{22}\right)\right)-\left(r_{1}, r_{2}\right),
$$

where we have made the dependence of the map $\tilde{T}($.$) on the probabilities$ $\Pi_{11}, \Pi_{22}$ explicit. If we introduce vector notation $r=\left(r_{1}, r_{2}\right)$ and $\Pi=$ $\left(\Pi_{11}, \Pi_{22}\right)$, we can write the key condition of the implicit function theorem as the requirement that the matrix $D_{\tau} W$, evaluated at that pair of steady states, is nonsingular.

By inspecting equations (28), (29), (30), (31), (32), (33), (34), (35) and (36), it is seen that for the first component of $W$ we have

$$
W_{1}\left(\left(r_{1}, r_{2}\right),\left(1, \Pi_{22}\right)\right)=T\left(r_{1}\right)-r_{1} \text { for } \forall r_{1}, r_{2}, \Pi_{22},
$$

where $T(r)$ is given by equation (8). To show this we first note that $\Pi_{11}=1$ implies $q(1,1)=1$. Substituting $q(1,1)=1$ into the relevant members of equations (33) yields the preference curve (26). Second, inserting $q(1,1)=1$ and $q(1,2)=0$ into (29), (30), and (31), and taking into 
account (32), we obtain the technology curve (24). Finally, it is easily seen that (35), (29), and (30) yield (23). A similar argument can also be made that $W_{2}\left(\left(r_{1}, r_{2}\right),\left(\Pi_{11}, 1\right)\right)=T\left(r_{2}\right)-r_{2}$ when $\Pi_{22}=1$.

From the above one can compute

$$
D_{r} W\left(\left(r_{L}, r_{H}\right),(1,1)\right)=\left(\begin{array}{cc}
T^{\prime}\left(r_{L}\right)-1 & 0 \\
0 & T^{\prime}\left(r_{H}\right)-1
\end{array}\right)
$$

at $\left(r_{L}, r_{H}\right)$. Thus, growth cycles exist in a neighborhood of $\left(r_{L}, r_{H}\right)$ provided $T^{\prime}\left(r_{L}\right) \neq 1$ and $T^{\prime}\left(r_{H}\right) \neq 1$.

Next, we consider the stability of an equilibrium under adaptive learning. Evans and Honkapohja (1994) show that the dynamics defined by (14) are locally stable - i.e. the trajectories starting from any point in a neighborhood of the equilibrium converge almost surely to the equilibrium - whenever a condition known as E-stability is satisfied. ${ }^{14}$ For E-stability it is required that the eigenvalues of $D_{T} \tilde{T}$, evaluated at equilibrium growth cycle, have real parts less than one. By continuity of eigenvalues and (38), this condition is met in a neighborhood of $\left(r_{L}, r_{H}\right)$ provided $T^{\prime}\left(r_{L}\right)<1$ and $T^{\prime}\left(r_{H}\right)<1$. This proves Proposition 1 .

\footnotetext{
${ }^{14}$ In fact, the algorithm needs to be supplemented with a "projection facility" to obtain local convergence with probability one. Evans and Honkapohja (1996) show that without a projection facility one can still obtain positive convergence results.
} 


\section{References}

[1] Azariadis, Costas (1993), Intertemporal Macroeconomics, Blackwell, Oxford.

[2] Azariadis, Costas and Allan Drazen (1990), "Threshold Externalities in Economic Development." Quarterly Journal of Economics 105, 501526 .

[3] Ball, Lawrence and N. Gregory Mankiw (1994), "A Sticky Price Manifesto." Carnegie-Rochester Conference Series on Public Policy 41, 127151.

[4] Beaudry, Paul and Michael Devereux (1993), "Monopolistic Competition, Price Setting, and the Effects of Real and Monetary Shocks." University of British Columbia, mimeo.

[5] Benhabib, Jess and Aldo Rustichini (1994), "Introduction to the Symposium on Growth, Fluctuations and Sunspots: Confronting the Data." Journal of Economic Theory 63, 1-18.

[6] Benhabib, Jess and Roger Farmer (1994), "Indeterminacy and Increasing Returns." Journal of Economic Theory 63, 19-41.

[7] Benhabib, Jess and Jordi Gali (1995), "On Growth and Indeterminacy: Some Theory and Evidence." C. V. Starr Center for Applied Economics Research Report 95-08.

[8] Benhabib, Jess and Roberto Perli (1994), "Uniqueness and Indeterminacy: On the Dynamics of Endogenous Growth", Journal of Economic Theory 63, 113-142.

[9] Blanchard, Olivier J. and Stanley Fischer (1989), Lectures on Macroeconomics, MIT Press, Cambridge.

[10] Brock, William A. (1975), "A Simple Perfect Foresight Monetary Model." Journal of Monetary Economics Vol 1, 133-150. 
[11] Bryant, John (1983), "A Simple Rational Expectations Keynes-Type Model." Quarterly Journal of Economics 98, 525-528.

[12] Calvo, Guillermo A. (1978), "On the Indeterminacy of Interest Rates and Wages with Perfect Foresight." Journal of Economic Theory 19, 321-337.

[13] Cass, David and Karl Shell (1983), "Do Sunspots Matter?" Journal of Political Economy 91, 193-227.

[14] Chamley, Christophe (1993), "Externalities and Dynamics in Models of Learning by Doing." International Economic Revieu 34, 1-27.

[15] Chatterjee, Satyajit, and Russell W. Cooper (1993), "Entry and Exit, Product Variety and the the Business Cycle." NBER Working paper 4562 .

[16] Chatterjee, Satyajit, Russell W. Cooper, and B. Ravikumar (1993), "Strategic Complementarity in Business Formation: Aggregate Fluctuations and Sunspot Equilibria." Review of Economic Studies 60, 795811.

[17] Cooley, Thomas F. and Edward C. Prescott (1995), "Economic Growth and Business Cycles." 1-38, in Cooley, Thomas F., ed., Frontiers of Business Cycle Research, Princeton University Press: Princeton NJ.

[18] Cooper, Russell W. and Andrew John (1988), "Coordinating Coordination Failures in Keynesian Models." Quarterly Journal of Economics $103,441-463$.

[19] Diamond, Peter (1982), "Aggregate Demand Management in Search Equilibrium." Journal of Political Economy 90, 881-894.

[20] Drugeon, Jean Pierre and Bertrand Wigniolle (1996), "Continuous Time Sunspot Equilibria and Dynamics in a Model of Growth." Journal of Economic Theory 69, 24-52.

[21] Evans George W. and Seppo Honkapohja (1994), "On the Local Stability of Sunspot Equilibria under Adaptive Learning Rules." Journal of Economic Theory 64, 142-161. 
[22] Evans, George W. and Seppo Honkapohja (1995a), "Adaptive Learning and Expectational Stability: an Introduction." ch. 4 in Learning and Rationality in Economics, ed. by A. Kirman and M. Salmon, Oxford: Basil Blackwell, 104-126.

[23] Evans, George W. and Seppo Honkapohja (1995b), "Local Convergence of Recursive Learning to Steady States and Cycles in Stochastic Nonlinear Models." Econometrica 63, 195-206.

[24] Evans George W. and Seppo Honkapohja (1996), "Economic Dynamics with Learning: New Stability Results." mimeo, University of Helsinki.

[25] Farmer, Roger (1991), "Sticky Prices." Economic Journal 101, 13691379.

[26] Farmer, Roger and Jang Ting Guo (1994), "Real Business Cycles and the Animal Spirits Hypothesis." Journal of Economic Theory 63, 42-72.

[27] Gali, Jordi (1994), "Monopolistic Competition, Business Cycles and the Composition of Aggregate Demand." Journal of Economic Theory $63,73-96$.

[28] Guesnerie, Roger and Michael Woodford (1992), "Endogenous Fluctuations." 289-412, in Laffont, Jean-Jacques, ed., Advances in Economic Theory Sixth World Congress, Vol. II, Cambridge University Press: Cambridge, UK.

[29] Hamilton, James D. (1989), "A New Approach to the Economic Analysis of Nonstationary Time Series and the Business Cycle." Econometrica $57,357-84$.

[30] Howitt, Peter and Preston McA fee (1992), "Animal Spirits." American Economic Review 82, 493-507.

[31] Kaminsky, Graciela (1993), "Is There a Peso Problem? Evidence from the Dollar/Pound Exchange Rate, 1976-1987." American Economic Review 83, 450-472.

[32] Kehoe, Timothy J, David K. Levine and Paul M. Romer (1992), "On Characterizing Equilibria of Economies with Externalities and Taxes as Solutions to Optimization Problems." Economic Theory 2, 43-68. 
[33] Lucas, Robert E. Jr. (1986), "Adaptive Behavior and Economic Theory." Journal of Business Supplement 59, S401-S426.

[34] Matsuyama, Kiminori (1995), "Complementarities and Cumulative Processes in Models of Monopolistic Competition." Journal of Economic Literature 33, 701-729.

[35] Romer, Paul (1987), "Growth Based on Increasing Returns Due to Specialization." American Economic Review, Papers and Proceedings $77,56-62$.

[36] Schmitt-Grohé, Stephanie (1995), "Comparing Four Models of Aggregate Fluctuations Due to Self-Fulfilling Prophecies." mimeo.

[37] Shleifer, Andrei (1986), "Implementation Cycles." Journal of Political Economy 94, 1163-1190.

[38] Silvestre, Joaquim (1993), "The Market-Power Foundations of Macroeconomic Policy." Journal of Economic Literature 31, 105-141.

[39] Startz, Richard (1994), "Growth States and Sectoral Shocks." manuscript, University of Washington, January 1994.

[40] Young, Alwyn (1993) "Substitution and Complementarity in Endogenous Innovation." Quarterly Journal of Economics 108, 775-808.

[41] Woodford, Michael (1991), "Self-Fulfilling Expectations and Fluctuations in Aggregate Demand." in New Keynesian Economics, N. Gregory Mankiw and David Romer eds., MIT Press, Cambridge.

[42] Xie, Danyang (1994), "Divergence in Economic Performance: Transitional Dynamics with Multiple Equilibria." Journal of Economic Theory $63,97-112$. 